\title{
Exploring Aluminum Alloy Metal Matrix Composites in EDM using Coupled Factor-level-present Worth Analysis and Fuzzy Analytic Hierarchy Process
}

\author{
K.O. Okponyia and S.A. Oke*
}

\begin{abstract}
This paper targets two improvement aspects of the electrical discharge machining (EDM) process. First, it formulates the EDM problem as an economic issue incorporating the present worth analysis into the factorlevel framework and solves it with the performance analysis flow diagram. Second, it conceptualizes the EDM process as imprecision and uncertainty and solves it with the fuzzy analytical hierarchy process (FAHP) approach. At present, these methods are not accessible to the EDM process engineer to machine the work material, AA6061/10\% $\mathrm{Al}_{2} \mathrm{O}_{3}$ AMMCs. In this study, the EDM process application using these methods on AA6061/10\% $\mathrm{Al}_{2} \mathrm{O}_{3} \mathrm{AMMCs}$ is considered. This paper investigates the use of fuzzy AHP multicriteria and the present worth method to produce a structured approach to model multi-response problem of EDM process parametric optimization concerning composite named $\mathrm{AA6061/10 \%} \mathrm{Al}_{2} \mathrm{O}_{3} \mathrm{AMMCs}$ to obtain a robust design and the best parametric selection. The selected performance measures for the inputs to attain the performance flow analysis using the present worth method are MRR $=17.932$ to $31.753 \mathrm{mg} / \mathrm{min}$, TWR $=0.171$ to $0.289 \mathrm{mg} / \mathrm{min}, \mathrm{SR}=8.228$ to $12.680 \mathrm{~mm}$ and $\mathrm{OV}=0.292$ to $0.406 \mathrm{~mm}$. The performance flow analysis reveals a present with a value of 1.604 based on the equivalence analysis of the flow diagram's positive and negative sides. The FAHP results showed the enhanced values of $0.1051,0.2290$, and 0.6658 for peak current, pulse on time, and duty factor, respectively. The approach is novel and has not been implemented elsewhere to solve the problem for the combination of materials studied.
\end{abstract}

Keywords: Fuzzy set, machining planning, present worth method, analytical hierarchy process.

Article Info: Received October 30, 2020; Revised January 30, 2021; Accepted April 5, 2021.

\section{INTRODUCTION}

It is mandatory to study the influence of different variables of electrical discharge machining (EDM) on performance to run the machine economically and effectively (Karthikeyan et al., 2012; Sanghani et al., 2020; Phate et al., 2020; Ilani and Khoshnevisan, 2020; Martinez-Alvarado et al., 2020). The EDM performance appraisal idea in non-traditional machining refers to the usual review of the EDM's performance on work materials and the global contribution to the operations and sustainability of the organization (Vignesh and Ramanujam, 2018; Upadhyay et al., 2019; Chocklingam et al., 2019; Sarma and Singh, 2020; Gupta et al., 2020). In this study, the EDM of the work material AA6061/10\% $\mathrm{Al}_{2} \mathrm{O}_{3}$ AMMCs is analyzed from machining economics' perspective by the present worth method whereby the values of the system's performance measures of overcut (OV), surface roughness (SR), material removal rate (MRR) and tool wear rate (TWR) are accompanied with the level information to define the

\footnotetext{
S.A. Oke* is with the Department of Mechanical Engineering, University of Lagos, Nigeria (email: sa_oke@yahoo.com).

* Corresponding author
} 
framework for computation. Computational experiments were performed, the discounting factor is evaluated. The AHP criteria weight values of Raji and Oke (2020) serve as input to the fuzzy analytical hierarchy process (FAHP).

Furthermore, choosing the most important process parameter in an EDM process is a major industrial challenge. Besides, there is difficulty in enhancing resource allocation with the knowledge of resource requirements for each $\mathrm{EDM}$ parameter during the machining of $\mathrm{Al} 6061 / 10 \% \mathrm{Al}_{2} \mathrm{O}_{3} \mathrm{AMMCs}$. Losses from the EDM process may be huge if improperly managed. This has stimulated the industry-wide drive to reduce losses by deploying an overall equipment effectiveness program anchored on manufacturing's six significant losses. Nevertheless, losses continue to threaten the EDM process's sustainability, which can be curtailed by deploying the necessary resources sufficient alone to service each parameter and not in excess. Also, the demand for more intricate parts, requiring special features in machine processing, and the corresponding increase in the cost of material and human resources combined with the pressure to remain sustainable is placing new pressures on the EDM process.

As a projected increase in the number of users for engineering parts is expected in the next few years, there is an urgent need to establish novel and innovative approaches to tackle the EDM system's ranking and resource distribution problem. The use of multi-criteria models, including fuzzy analytical hierarchy, is a crucial part of this problem's scientific response. It is envisaged that meeting this challenge would require models beyond the traditional ones that use crisp numeric values to those that are capable of capturing uncertainty and imprecision of the EDM process in manufacturing AA6061/10\% $\mathrm{Al}_{2} \mathrm{O}_{3}$ AMMCs (Afolayan et al., 2020; $\mathrm{Li}$ et al., 2020; Yazdi et al., 2020; Song et al., 2021; Zhang et al., 2021).

\section{LITERATURE REVIEW}

\subsection{General}

The FAHP is a result-oriented uncertainty tracking tool developed to overcome the shortcomings of the analytical hierarchy process by activating a fuzzy mechanism that interfaces with all the phases of the AHP. In the selection of EDM process parameters during the machining of AA6061/10\%Al2O3AMMCs, the FAHP is deployed to bridge the knowledge gap of tracking uncertainties in the modeling analysis exercises. The FAHP utilizes the fuzzy elements to translate the values into linguistic variables that can be easily interpreted, unlike the traditional AHP that awards crisp numeric values to the parameters. To date, a significant share of research efforts on engineering practices has focused prioritization using the AHP elements of goal definition, development of importance scale, comparison of factors, and a final ranking of parameters.

An exciting body of knowledge on EDM contributed to predicting and optimizing EDM process parameters
(Das et al., 2014). An inquisitive attempt was made on these publications to know if they offer ideas on selecting the process parameters. Those publications include Pradhan and Biswas (2008) that predicted the MERR response of the tool steel (AISI D2) using the neuro-fuzzy-based model. The second work, Mahdavinejad (2008), also optimizes the EDM process by applying the neural approach. Maurya et al. (2019) tailored research to a comprehensive survey to understand the broad range of optimization used in the wire-EDM process while on superalloys (i.e., titanium type). Rao and Pawar (2009) channeled efforts to enhance a WEDM process's responses through parametric optimization accomplished by the artificial bee colony approach. Chiang (2008) elaborated on how $I_{p}$, voltage, and Ton control the response (electrode wear proportion, MRR, and Ra. Jaharah et al. (2008) studied the tool steel workpiece (i.e., AISI H3) while removing the materials with a copper electrode. The responses were the MRR, wear rate of an electrode, and surface roughness. Sahu et al. (2019) focused on metal removal for A2 steel workpieces. This was achieved using factorial design, artificial neural network, and genetic algorithm ANOVA approach. The EDM process worked and confirmed the feasibility of the models. Lajis et al. (2009) machined ceramics (tungsten carbide) using a graphite-based electrode, but the Taguchi scheme was deployed for the optimization. Kuppan et al. (2007) obtained representation for the roughness average and the MRR in a drilling endeavor using Inconel 718 as the work material.

Payal et al. (2008) used the EDM process to understand the responses (surface roughness and MRR) using tool steel (EN 31) and electrodes (graphite and copper brass). Asilturk and Cunkas (2010) modeled the system's response (surface roughness) by deploying the multiple regression model and artificial neural network for the representation. Fazlollahtabar and Gholizadeh (2020) examined the influence of EDM parameters on responses (electrode corrosion percentage, material removal rate, and surface roughness) using a regression model (i.e., fuzzy probability type). It further employed a fuzzy adaptive neural network to establish the optimal levels of the outputs. Kanagarajan et al. (2008) studied the system's responses (i.e., MRR and surface roughness) while the process parameters were fixed at Ip, flushing pressure, Ton, and electrode notation. However, the response surface methodology was used for the representation. Pradhan et al. (2009) predicted the response (surface roughness) of a process using two neural network models and experimental outcomes. Puertas et al. (2004) examined EDM responses (electrode wear, MRR, and surface roughness) and how the process parameters direct them. Dewangan et al. (2020) examined the micro-EDM process parameters to machine Ti-6A1-4V, and fuzzy TOPSIS was used in that instance. Chen and Mahdivan (2000) approximated the values of responses (i.e., surface quality and MRR) by an empirical model and used mild steel as the work material. Rao et al. (2008) considered the response (MRR) of a die-sinking EDM) and elaborated on how 
various parameters influence it while the multiperception neural network approach was used as the representation. Das et al. (2013) focused on two responses (MRR and surface roughness) to determine an EDM process's optimal conditions. The weighted principal component analysis was used as the mathematical tool, while the tool material was the EN 31 tool steel. Lin et al. (2001) applied a Taguchi scheme to enhance the machining surfaces by integrating the EDM process and ball burnishes machining. Ilani and Khoshnevisan (2020) utilized acrylonitrile butadiene styrene with a thin layered coat of copper in EDM electrode tooling. Martinez-Alvarado et al. (2020) employed a categorization scheme, a fuzzy inference scheme, to control pulses in an electrochemical discharge machining process.

\subsection{Studies related to the present worth method}

To the best of the authors' knowledge, the literature review on previous research about present worth is nonexistent. At best, authors have analyzed cash flows of engineering projects by infusing fuzzy set theory ideas into the framework, such as demonstrated by Chiu and Park (1994). Since this attempt, very scanty applications of the present worth criterion have been made to engineering and general practices. Unfortunately, no successful application has been reported in the EDM field, making such an application in the current study novel and innovative. More recently, Maravas and Pantouvakis (2018) analyzed the present value of an engineering project to incorporate uncertainty. In an exciting application, fuzzy methods were introduced in cash flow analysis for construction managers to monitor the direction of cash flow during the valuation process (Boussabaine and Elhag, 1999). In a study, Zizlavsky (2014) evaluated the prospect from an economic perspective using the net present value method. Doss et al. (2015) analyzed the financial potential of an institution by deploying the net present worth analysis as a tool. Given the above studies on the net present with analysis, although its application is wide-ranging, it has not yet been deployed to the machining area despite the need to understand the financial aspects of machining in this long-standing metal removal area of engineering practice.

\subsection{Research problem, the scope of study, objectives, and contributions}

\subsubsection{The selection problem regarding uncertainty in EDM parameters}

The process engineer decides how many labor hours to utilize in production to machine the work material AA6061/10\%Al2O3AMMCs using the EDM process. The engineer also decides on the cost, quantity, and source of the dielectric fluid to use. The engineer reviews whether to use kerosene, de-ionized water, or reusable plant waste oil such as sunflower waste oil. Does the work require more space than being used to warrant additional space rentals? How much and what quantity of electricity do we use? The answers to these questions and issues are uncertain and imprecise. Apart, these resources in the EDM process may be attributed to the parameters considered for processing, such as the pulse on time, peak current, and duty factor. However, decisions must be made to machine the workpiece, AA6061/10\% $\mathrm{Al}_{2} \mathrm{O}_{3} \mathrm{AMMCs}$, and resources should be deployed to achieve this aim. However, what quantity of these resources should be deployed to each parameter? This is unknown. At what time should we process these resources, and at what quantity should they be prosecuted? These are qualitative decisions that should be transmitted into quantitative terms.

Nevertheless, linguistic terms that these resources are expressed in should be changed to crisp numeric values. Should we continue to work in uncertainty and impression without seeking a scientific solution? Can a fuzzy system be combined with an analytical hierarchy process to help the process engineer in resource distribution, leading to ranking and prioritization problems?

The electrical discharge machinist sets parameters at different thresholds according to some anticipated requirements. The parameters may include pulse ontime, duty factor, and peak current. Each of these parameters consumes both material and human resources (time). At present, the process engineer uses discretion to evaluate what allocation of the limited maintenance resources to distribute to each parameter. Since judgment is based on intuition at the time, the distribution of the resources may be as needed. The operator may announce success at machining the material. There is no conflict with other operators since there is no issue where resources are dragged between two operators. However, the situation is different when too little or too many resources are allocated to the operators. For the case of too much resource allocation to an operator, wastage occurs, and this is against the argument by the overall equipment effectiveness campaign in industries. However, if less than the required resources are given to the work center, the operator may not complete the job. This has negative consequences on customer retention and the goodwill of the company. There is an urgent need to tackle this problem with a scientific tool. Besides, the process engineer requires a selection method to overcome the challenge posed by the appropriate tool's unavailability to solve the problem. Also, the EDM literature requires a selection methodology that possesses novelty to tackle resource distribution's complicated task to the parameters.

\subsubsection{Observations and scope}

From the review of the literature to capture the area of the EDM process, some notable gaps and observations are as follows:

1. EDM process is an expanding non-traditional machining system, and based on customers' demand, it will continue to grow. However, it requires improvement for value-added services.

2. Selection of value-added EDM services parameters is essential but currently conducted with experience, 
conservative attitude, and investment of considerable efforts in time and money. This problem in the EDM literature needs to be corrected urgently. Scientific approaches are needed to correct this problem with the utmost attention.

3. An important aspect of the problem not attempted is a parametric selection of materials in uncertainty and imprecision conditions. The fuzzy analytical hierarchical process has not yet been used to capture the EDM process where parameters are specified as the peak current, pulse on-time, and duty factor. Responses are the overcut, material removal rate, and surface finish. The materials name $\mathrm{A} 16061 / 10 \% \mathrm{Al}_{2} \mathrm{O}_{3} \mathrm{AMMCS}$ have not been processed with the selected parameter under imprecise and uncertain conditions.

4. The common parameter used in the literature is electrode rotation (Kanagarajan et al., 2008), peak current (Kuppan et al., 2007) flushing pressure (Kanagarajan et al., 2008), duty cycle (Pradhan and Biswas, 2008).

5. The influential methods used in EDM process modeling and analysis are the response surface methodology (Kanagarajan et al., 2008), Taguchi scheme (Lajis et al., 2009), weighted principal component analysis (Das et al., 2013), neural control approach (Mahdavinejad, 2008), approach (Rao et al., 2008), artificial bee colony (Rao and Pawar, 2009), ANOVA (Chiang, 2008) multiple-regression approach coupled with artificial neural network (Asiturrk and Cunkas, 2010), neural network (Pradhan et al., 2009), neuro-ferry model (Pradhan and Biswas, 2008).

6. The manager EDM types are the WEDM (Rao and Pawar, 2009), die-sinking EDM (Rao et al., 2008), and the general type (Lin et al., 2001; Puertas et al. 2004).

7. The observable responses are roughness average (or surface roughness/finish) (Pradhan et al., 2009, Kanagarajan et al., 2008; Jaharah et al., 2008; Kuppan et al., 2007; Puertas et al., 2004; Chiang 2008; Asilturk and Cunkas, 2010, Chen and Mahdivian, 2000, Payal et al., 2008 das et al., 2013), MRR (Pradhan and Biswas, 2008, Kanagarajan et al., 2008, Das et al., 2013; Payal et al., 2008, Rao et al., 2008, Chen and Mahdivian, 2000, change 2008, Puertas et al., 2004, Kuppan et al., 2007, Jaharah et al., 2008), electrode wear (rate) (Puertas et al., 2004, Jaharah et al., 2008), electrode corrosion percentage (Fazlollahtabar and Gholizadah, 2020).

8. The materials used are mainly Ti-6A1-4V alloy (Dewangan et al., 2020), A2 steel (Sahu et al., 2019).

In the proceeding part of this section, previous research on the optimization procedures of EDM was listed. However, these comprehensive studies' limitation is that minimal emphasis on the uncertainty involved in their processing was considered. Besides, none of the studies has treated the machining practice from the economic viewpoint vis-à-vis the present worth method's application. Furthermore, the synergic benefits of fusing the fuzzy analytic hierarchy and present worth method as a single method were not exploited in this mentioned literature. To exploit this potential, the current author has deployed a method that integrated the FAHP and presented the worth method in an innovative approach to understanding the EDM process parameters' attributes better.

The scope of this study entails the following issues: 1. The work material used shall be AA6061/10\% $\mathrm{Al}_{2} \mathrm{O}_{3}$ AMMCs (Kandpal et al., 2017).

2. The EDM process parameters shall be limited to pulseon time, peak current, and duty factor. Simultaneously, the resources are specified as the tool wear rate, overcut, material removal rate, and surface roughness (Kandpal et al., 2017).

3. The present worth method shall be used in which the number on line grading is represented as the levels. In this scenario, the EDM process's responses are marked in the upper, positive side of the number line, while the EDM parameters are marked on the lower, negative side of the number line. The idea of equivalence of the normalized quantities on each side of the number line shall apply.

4. In implementing the present worth method, the discounting factor's coefficients will be the normalized values, a discounting factor of P/A will apply. The interest rate in a developing country noted as $12 \%$ will be applicable while the time elements will be replaced with the parameters' levels and the EDM process's responses.

5. In the computation of the geometric mean of the parameters for weight determination using the fuzzy analytical hierarchy process method, Buckley's 1985 proposal, a classic measure, shall apply.

6 . The center of the area concept will be used to convert the fuzzy geometric weights into weights of crisp numeric values.

7. The fuzzy analytical hierarchy process that utilizes extent analysis to determine the weights of parameters will be used in this work

8. Experimental data of Kandpal et al. (2017) will be used for model validation.

\subsubsection{Objectives}

So far, a study that focuses on determining a strategy that may be pursued for resource disbursement through the parametric determination of the best EDM parameter remains under-studied. Consequently, it is undecided how the process engineer in the EDM process can manage the prosecution of process parameters such as pulse on time, duty factor, and peak current in cooperation with the EDM process machinist. It is unclear how this could be achieved in the current depressed economy globally and the strong drive for sustainability and conservation of resources. The objectives of this paper are as follows:

1. To establish and investigate the EDM process parameters in the context of uncertainty and imprecision concerning a set of specified responses.

2. To analyze the results of using fuzzy analytical hierarchy process under the condition of geometric mean for the EDM process of $\mathrm{AA} 6061 / 10 \% \mathrm{Al}_{2} \mathrm{O}_{3} \mathrm{AMMCs}$. 
3. To study the outcome of employing the fuzzy analytical hierarchy process subject to extent analysis method of weight determination for the EDM process of AA6061/10\% $\mathrm{Al}_{2} \mathrm{O}_{3} \mathrm{AMMCs}$.

4. To establish the present worth technique as a diagnostic tool for the EDM process's health monitoring by relating parameters to responses in a defined compounding factor context.

\subsubsection{Contributions}

Through an accomplishment of the study objectives, the following important contributions should strengthen the EDM literature:

1. Insights characterize the EDM process's parametric selection as a multi-criteria set of inputs that will help the process engineer make realistic decisions concerning the deployment of resources and other issues to parameters of the most significant interest to the system.

2. The inter-relationship of parameters of the EDM process and responses is illustrated with the present worth method, making it easy for the process engineer to judge the company's position concerning stability and relative to sustainability issues.

3. The uncertain nature of process engineer's judgments is evaluated using the fuzzy analytical process and how the EDM process's qualitative attributes can be converted into quantitative meanings for decision making.

4. The complicated EDM process is assessed to develop a deep insight into how the process engineer can relate the EDM process parameters in a situation of uncertainty and limited resources.

\section{THE PROPOSED METHODOLOGY}

\subsection{The research problem}

However, another aspect worth studying is a suggestion of new procedures in the EDM process's performance measures since it is believed that existing methods do not reflect reality. In practical situations, the complication of the EDM economic problems offers challenges for numerous analytical methods. Nonetheless, in this study, the present worth method is deployed as a recent introduction to the EDM process associated with multi-criteria structures. It has potential success in solving the machining economics problem and declaring the state of the EDM process as either healthy or unhealthy. Strong supports for these assertions could be found in Zizlavsky (2014) and Maravas and Pantouvakis (2018). By using the outcome of normalization of the EDM process parameters of pulse on time, peak current, and duty factor, for the work material, AA6061/10\% $\mathrm{Al}_{2} \mathrm{O}_{3} \mathrm{AMMCs}$, and the performance measures of overcut, tool wear rate, material removal rate, and surface roughness, with experimental data drawn from Kandpal et al. (2017), the computational investigation of the present worth method in EDM was done. The results show the effectiveness of the present worth method in resolving the formulated EDM economics problem.

\subsection{Fuzzy analytical hierarchy process}

The fuzzy analytical hierarchy process is an approach in the multi-criteria assessment of EDM process parameters to establish the comparative weights of the parameters (Afolayan et al., 2020; Li et al., 2020; Yazdi et al., 2020; Song et al., 2021; Zhang et al., 2021). It is similar to AHP, but the fuzzy AHP approach positions the AHP dimension into the fuzzy triangle dimension to attain priority ranking parameters (Li et al., 2020; Song et al., 2021). For the traditional ranking for the parameters, the traditional importance scale has six levels, recognized by the numbers $1,3,5,7,9$ as the first five numbers and 2, 4, 6, 8 as the intermediate numbers (Afolayan et al., 2020; Li et al., 2020). These are called crisps or crisp numeric values. Corresponding to this importance scale along the fuzzy AHP side, there are five scales where 1 on the AHP scale is translated to (1, $1,1)$, called the fuzzy number (Li et al., 2020). For the last item on the scale of 9 , the equivalence $(9,9,9)$ is the fuzzy number. However, the equivalence of 3,5 , and 7 on the fuzzy scale is differently formed. The actual number of the AHP scale is retained at the middle while a unit, 1, is the substrate to make the third value. For instance, " 3 " that represents "moderate importance" on the AHP scale is the "weakly importance" on the fuzzy scale. However, the fuzzy number is $(2,3,4)$.

The steps taken in the fuzzy analytical hierarchy process approach are listed below (Afolayan et al., 2020; Li et al., 2020; Yazdi et al., 2020):

Step 1: The scale of relative importance used in the analytical hierarchy process method is changed to a fuzzy scale of relative importance, which uses fuzzy numbers.

Step 2: A pair-wise comparison matrix is developed using the scale of relative importance.

Step 3: The pair-wise comparison matrix obtained will be changed to fuzzy numbers using the fuzzy scale of relative importance. To change the values of fractions, the formula used is given as:

$$
\approx_{A}^{-1}=(l, m . u)^{-1}=\left(\frac{1}{u}, \frac{1}{m}, \frac{1}{l}\right)
$$

Step 4: The fuzzy geometric mean $\underset{r_{i}}{ }$ is calculated and multiplicates each value in each column. The formula to multiply fuzzy numbers is given below:

$$
\begin{array}{r}
\tilde{A_{1} \times \tilde{A}_{2}}=\left(l_{1}, m_{1}, u_{1}\right) \times\left(l_{2}, m_{2}, u_{2}\right) \\
=\left(l_{1} \times l_{2}, m_{1} \times m_{2}, u_{1} \times u_{2}\right)
\end{array}
$$

Step 5: The fuzzy weights $\tilde{w}_{i}$ are calculated using:

$$
\approx \approx \underset{w_{i}}{\approx}=\underset{r_{i}}{\approx} \times\left(\widetilde{r_{1}}+\approx \tilde{r}_{2}+\tilde{r}_{3}\right)^{-1}
$$

Step 6: The fuzzy weights will then be changed to numerical values using the formula:

$w_{i}=\frac{l+m+u}{3}$

Irrespective of the type of EDM system, whether diesinking EDM (Rao et al., 2008), hole drilling EDM 
(Kuppan et al., 2007), or wire EDM (Rao and Pawar, 2009; Maurya et al., 2019), most of the latest technologies, which are practically used to work on aluminum alloys demand the skillful combination of EDM process parameters. The three common parameters of the EDM process, namely the peak current, pulse on time, and duty current, should be considered such that the economy of resources is guaranteed (Kandpal et al., 2017). Acknowledging the differences in the importance of the process parameters offers the power to discriminate among the parameters. It gives a sense of direction of locating the scarce resources and how much they allocate to the different parameters. Moreover, in recent years managing EDM assets and the machining infrastructure occurs in a chaotic global economic and competitive scenario. There is, therefore, intense pressure on process engineers to safeguard the sustainability of the process and ascertain the relative importance of each parameter in the system. In the present scenario, fuzzy AHP is one of the latest advances in manufacturing process parametric selection. However, there is no literature evidence that it has been used to select the EDM process parameters while the work material is the AA606/10\% $\mathrm{Al}_{2} \mathrm{O}_{3}$ AMMCs (Kandpal et al., 2017). This paper presents an innovative version of the fuzzy AHP, one of the latest advancements in techniques, the present worth-assisted fuzzy AHP. It is a conceptualized integration of present worth and the fuzzy analytical hierarchy process. It transmits the EDM process's economics into linguistic variables where the EDM parameters, the pulse on time, peak current, and duty factor are prioritized. It is at variance with its crisp numerical value approach in the traditional prioritization scale.

\subsection{The present worth-assisted fuzzy analytical hierarchy process}

In the EDM process, the assessment of the most appropriate parameters in the machining of the work material, AA6061/10\% $\mathrm{Al}_{2} \mathrm{O}_{3} \mathrm{AMMCs,}$ is a strategic concern that may influence the operational efficiency of the plant work climate among the EDM operators and the sustainability of the plant in the long run. In this paper, three EDM process parameters are, pulse on time, peak current, and duty factor, are considered (Kandpal et al., 2017). The purpose of this paper is to offer a structure to manage the EDM process parameter through a selection process with the combined present worth method and fuzzy analytical hierarchy process proactively. For this purpose, integrating the fuzzy system with an analytical hierarchy process and controlling the parameters and responses having conflicting goals for a process parametric selection problem in the EDM process with the $\mathrm{AA} 6061 / 10 \% \mathrm{Al}_{2} \mathrm{O}_{3} \mathrm{AMMCs}$, as the work material, is essential for better planning and to obtain the best parameter.

The AHP is used to establish the weights deployed in the fuzzy AHP method, to prioritize the parameters such that the process engineer could decide concerning the process enchantment. Furthermore, fuzzy logic is employed to transform the qualitative assessment. This study, however, has taken a different perspective by looking at how to integrate the present worth method and the fuzzy AHP method. The aim of the fuzzy analytical hierarchy process model is the allotment of the scarce and restricted EDM resources and equipment to machine the work material, AA6061/10\% $\mathrm{Al}_{2} \mathrm{O}_{3} \mathrm{AMMCs}$, in an allotted time and ascertain the economic distribution of resources for the actualization of the EDM parameters (material and human resources) during the manufacturing process. The use of educated guess and instruction in these circumstances may not achieve total satisfactory outcomes because the associated factors such as labor hours, some dielectric materials available, space to conduct the machining, and power availability are frequently fuzzy.

In a sustainable context, coupled with a gradually changing competitive and responsive engineering product market, planning for the EDM parameters and responses in machining the work material, AA6061/10\% $\mathrm{Al}_{2} \mathrm{O}_{3} \mathrm{AMMCs}$, has been considered using the framework of optimum selection for the process engineer in the EDM process. To attain a realistic result, fuzzy triangular numbers and the idea of the present worth method are used to formulate the problem. For the fuzzy aspect, the process parameters' crisps numerical values are transformed into fuzzy numbers, thereby making the data uniform. These numbers are the original ones obtained from the design matrix for the EDM parameters obtained from Raji and Oke (2020). The fuzzy geometric mean is evaluated to obtain the criteria weight based on the fuzzy AHP method. For the present worth method aspect of the model, the experimental values of Kandpal et al. (2017) are transferred using a linear normalization method of Cekas (2014) to obtain the normalized values are then used as flow quantities at the positive and negative sides of the number line system whose horizontal graduation is dictated by the levels of the parameters and responses. The initial performance flow diagram constituting responses (output) on the positive side and parameters (input) on the negative side is transferred into an equivalent flow diagram that calculates the final directions of the flows according to the overall sum of all flows for each of the parameters and responses at each point of level determination.

The present worth formula that considers the factor and coefficients is then used. The final result is obtained as a positive or negative value to reflect if the system is healthy or unhealthy, respectively. The proposed approach was developed to formulate a present worth assisted fuzzy analytical hierarchy to reduce resource wastage under uncertain situations and select the best parameter to machine the work material, AA6061/10\% $\mathrm{Al}_{2} \mathrm{O}_{3} \mathrm{AMMCs}$, in an EDM process. The fuzzy analytical hierarchy process was deployed to rank the EDM process's parameters more realistic for the decision problem more realistic the machining situation of AA6061/10\% $\mathrm{Al}_{2} \mathrm{O}_{3} \mathrm{AMMCs}$ solution problem was computationally achieved. 
Furthermore, a significant drawback of the fuzzy analytical hierarchy process as an uncertainty tracking method cum prioritizing approach is its inability to account for the electrical discharge machining's economic aspect. Fuzzy AHP cannot account for the interest rate change on borrowed capital. How can we track the quality of responses from the EDM process associated with the parameters while the factors' levels are considered? This significant drawback has been overcome by introducing the present worth method into analyzing the fuzzy AHP method. The introduction of the present worth method into the evaluation framework that contains fuzzy AHP improves the EDM process evaluation's economic aspect.

Furthermore, the present worth method is a straightforward approach with factors that could be easily understood and applied in situations. Thus, it is anticipated that the introduction of the present worth method will promote yet another effective model to enhance the EDM process's performance in machining the work material, AA6061/10\% $\mathrm{Al}_{2} \mathrm{O}_{3} \mathrm{AMMCs}$. It serves as a performance check for workers. The company's consciousness is losing some money when wastage of materials exists for the EDM process to be resource prudent in management. The multiplier effect of the interest rate on the organization's inability raises some burdens in the EDM process workers' minds and the necessity to pursue resource management prudence with urgency and caution. Hence, this study on selecting EDM process parameters using present worth assisted fuzzy analytical hierarchy has been chosen to expand the process engineer's insight into the EDM process and the selection strategy to adapt innovatively.

\subsubsection{Present worth method}

The present value concept is borrowed from economics and finance into engineering as an engineering economics principle additionally identified as the present discounted value (Boussabaine and Elhag, 1999; Maravas and Pantouvakis, 2018). It refers to a projected value stream established at an instant of assessment (Zizlavsky, 2014). The current value of all inputs (parameters) and outcomes (responses) at the different assessment levels for all the performance flow is given a stated return rate. The idea is to drive the operational machining section to be conscious of resource usage since it is an economic center. It is assumed that the money used for the business is borrowed, and prudence in the allocation and use of EDM resources reduces EDM management's burden in sourcing materials. So the current value of the forthcoming performance of the EDM process is measured in terms of parametric values and the outcome of responses when performance elements are discounted by a rate, which depends on the interest rate.

Applying the present worth theory is linked to a normalization technique since the parameters and responses' values are not the same. The parameters of interest include the peak current that is measured in ampere. The peak current symbolizes the maximum quantity of current in which the responses can obtain quickly. The pulse on-time is measured in $\mu \mathrm{s}$. It refers to when the voltage is operated across the work material (AA606/10\% $\mathrm{Al}_{2} \mathrm{O}_{3} \mathrm{AMMCs}$ ) and the wire electrode. At this instant, a significant increase in the cutting rate is experienced due to the chain effect. The single pulse that is held by the discharge energy grows to increase the $\mathrm{T}_{\text {on }}$. The duty factor is expressed in percentage, often relative to the ON time. For instance, in machining, for the work material AA606/10\% $\mathrm{Al}_{2} \mathrm{O}_{3} \mathrm{AMMCs}$, a $70 \%$ duty factor refers to a signal, ON $70 \%$ of the situation and $30 \%$ OFF the same situation. It is often treated as unitless and typical to observe values written in decimals as 0.05 or similar values.

The responses considered in machining the work material, AA606/10\% $\mathrm{Al}_{2} \mathrm{O}_{3} \mathrm{AMMCs}$, are the material removal rate, measured in $\mathrm{mg} / \mathrm{min}$. Others are tool wear rate, measured in $\mathrm{mg} / \mathrm{min}$, surface roughness expressed in $\mathrm{mm}$, and overcut that is represented in $\mathrm{mm}$. The MRR defines the amount of the work material (i.e., AA606/10\% $\mathrm{Al}_{2} \mathrm{O}_{3} \mathrm{AMMCs}$ ), which is eliminated per minute as the EDM machine is operated. The greater the material eradicated per minute, the greater the value of the material removal rate. The tool wear rate, also referred to as the tool wear index, is evaluated using signals or predictions. It refers to the tool's EDM effect, often eradicating part of the tool to deform its configuration. In machining, tool wear is ascribed to a processing speed that is extremely low or a substantially high feed rate. The surface roughness is a change in the surface's heights on the work material being evaluated, usually measured as the roughness average, $\mathrm{R}_{\mathrm{a}}$. The overcut refers to a machine cut, creating an undesired gap between the EDM tool on its every side and the machined hole, often in the wire EDM type.

This paper presents an exciting and rarely studied aspect of electrical discharge machining. It excites us because, despite the EDM area's maturity, hybridization with engineering economics appears not to have been attempted. Thus, the innovative analysis of EDM parameters, responses, and the interest rate charged on money for the business in a performance (traditionally called cash) flow diagram is expected to agitate research and enhance performance. Using a present-worthassisted fuzzy analytical hierarchy process (PWFAHP), the EDM of the work material Al6061/10\% $\mathrm{Al}_{2} \mathrm{O}_{3} \mathrm{AMMCs}$ was successfully analyzed for parametric selection. The sources are scarce in an EDM process. Electric power needs to be secured at cost, and labor hours will be utilized at a rate.

Furthermore, the workspace needs to be rented at cost, and die-electric material (i.e., oil or de-ionized water) needs to be purchased at cost. Thus, these resources need to be shared for any work material to be processed in the EDM shop. Nevertheless, it is unknown whether the peak current, duty factor, or pulse-on time takes the greater share of this resource or not. This has not been scientifically verified for the work material $\mathrm{Al} 6061 / 10 \% \mathrm{Al}_{2} \mathrm{O}_{3} \mathrm{AMMCs}$.

The work uses the present worth theory in engineering economics where the experimental data 
K.O. Okponyia and S.A. Oke

from the literature fed into the performance flow diagram. The conventional cash flow diagram has been traditionally treated. Arrows represent the inflow of funds and their outflows on the opposite sides of the cash flow diagram (herewith referred to as the performance flow diagram). The experimental values of pulse-on time, duty factor, peak current as parameters, and the overcut, material removal rate, and surface roughness as responses are all normalized first to permit an adequate comparison (Table 1). The final values are then tried on the performance flow diagram with the parametric values and responses treated on opposite the performance flow diagram's opposite sides. The work material whose experimental data is obtained is from Kandpal et al. (2017), and it is the $\mathrm{Al6061/10 \%} \mathrm{Al}_{2} \mathrm{O}_{3}$ AMMCs. The PWFAHP is used to select the EDM process parameters for enhanced resource (material and non-material) distribution to process parameters, notably the pulse on time, duty factor, and peak current. The goal is to obtain the utmost responses regarding the overcut, material removal rate, and surface roughness. It is argued that both the responses and parameters in an EDM process to machine the work material $\mathrm{Al} 6061 / 10 \% \mathrm{Al}_{2} \mathrm{O}_{3} \mathrm{AMMCs}$ should be incorporated into the analysis.

Unfortunately, the previous study in this area, Raji and Oke (2020), has exclusively omitted the analysis responses. Besides, it is vital to translate analysis of the EDM process to economic terms since it involves using resources that are economically driven. To sustain the company by purchasing materials for EDM such as dielectric materials (i.e., oil or de-ionized water) and pay for labor hours, funds must be secured, often charged at the economical rate of interest. The present worth analysis involving the parameters, responses, and the interest rate would aid a good analysis of the EDM parametric analysis.

To normalize, consideration was first given to the parameters and then responses. The parameters' data may be referred to in Table 1 of Kandpal et al. (2017). However, to promote an understanding and the structure, it is described here. It has three factors and three levels. For the first factor, peak current, the three levels are 6A, 10A, and 14A for levels 1, 2, and 3, respectively. For the second factor, pulse on time, the first, second, and third levels are $75 \mu \mathrm{s}, 100 \mu \mathrm{s}$, and 20 $\mu \mathrm{s}$, respectively. Lastly, the third factor, duty current, has three levels at $0.5,0.6$, and 0.7 , respectively. Normalization is essential in this case since the parameters have different units; peak current and pulseon time have A and $\mu \mathrm{s}$ as units, respectively, while the duty factor is unitless. Normalization is commenced with the first factor, peak current, using Equation's formula (5).

$$
Q_{\text {latest }}=\left(Q-Q_{\min }\right) /\left(Q_{\max }-Q_{\min }\right)
$$

Where $Q_{\text {latest }}$ is the latest value obtained from the conversion exercise, $Q$ is the value of the data to be transformed into a normalized form. $Q_{\min }$ is the minimum value obtained from the array of numbers considered, and $Q_{\max }$ is the maximum value obtained from the array of numbers considered.

Using the value of the first level's peak current, the normalization value of 0 for the original value of $6 \mathrm{~A}$ is obtained (Table 2 of Kandpal et al., 2017). The procedure is repeated for all the eight other entries to obtain a range from 0 to 1 (Table 1 ).

For the normalization of responses, the value from Table 4 of Kandpal et al. (2017) is utilized. Since three levels are desired average of the values for nine sets of values are used. To obtain the value to response under level 1 of MRR, the average values of MRR from runs 1 to 9 are taken (Tables $2 \mathrm{a}$ and $2 \mathrm{~b}$ ).

\subsubsection{Analysis using the Present worth method}

The appropriate equation for the present worth approach is

Present worth $=$

$$
\begin{aligned}
& -P C_{n}(P / A, i, t)-P T_{n}(P / A, i, t)-D F_{n}(P / A, i, t) \\
& +M R R_{n}(P / A, i, t)+T W R_{n}(P / A, i, t)+S R_{n}(P / A, i, t) \\
& +O V_{n}(P / A, i, t)
\end{aligned}
$$

where $P C_{n}$ is the normalized value for peak current, $P T_{n}$ is the normalized value for a pulse on time, $D F_{n}$ is the normalized value for duty factor, $M R R_{n}$ is the normalized value for material removal rate, $T W R_{n}$ is the normalized value for tool wear rate, $S R_{n}$ is the normalized value for surface roughness, and $O V_{n}$ is the normalized value for overcutting

$i$ is $12 \%$ (the interest rate at present in Nigeria)

\begin{tabular}{|c|c|c|c|c|c|c|c|c|c|c|}
\hline \multirow[t]{3}{*}{ Levels } & \multicolumn{6}{|c|}{ Parameters } & \multirow{2}{*}{\multicolumn{4}{|c|}{$\begin{array}{c}\text { Responses } \\
\text { Current study }\end{array}$}} \\
\hline & \multicolumn{3}{|c|}{$\begin{array}{l}\text { Kandpal et al.’s (2017) } \\
\text { data }\end{array}$} & \multicolumn{3}{|c|}{ Current study } & & & & \\
\hline & $\begin{array}{l}\text { Peak } \\
\text { current } \\
\text { (A) }\end{array}$ & $\begin{array}{l}\text { Pulse } \\
\text { on } \\
\text { time } \\
\left(\mu_{\mathrm{s})}\right.\end{array}$ & $\begin{array}{l}\text { Duty } \\
\text { factor }\end{array}$ & $\begin{array}{l}\text { Peak } \\
\text { current } \\
\text { (A) }\end{array}$ & $\begin{array}{l}\text { Pulse on } \\
\text { time } \\
\left(\mu_{\mathrm{s})}\right.\end{array}$ & $\begin{array}{l}\text { Duty } \\
\text { factor }\end{array}$ & $\begin{array}{l}\text { Material } \\
\text { removal } \\
\text { rate (MRR), } \\
\mathrm{mg} / \mathrm{min}\end{array}$ & $\begin{array}{l}\text { Tool } \\
\text { wear } \\
\text { rate } \\
\text { (TWR), } \\
\mathrm{mg} / \mathrm{min}\end{array}$ & $\begin{array}{l}\text { Surface } \\
\text { roughness } \\
\text { (SR), } \\
\mu_{\mathrm{m}}\end{array}$ & $\begin{array}{l}\text { Overcut } \\
(\mathrm{OV}), \\
\mathrm{mm}\end{array}$ \\
\hline 1 & 6 & 75 & 0.5 & 0 & 0.5 & 1 & 0 & 0 & 0.504 & 0 \\
\hline 2 & 10 & 100 & 0.6 & 0 & 0.2 & 1 & 0.605 & 0.754 & 0 & 0.737 \\
\hline 3 & 14 & 200 & 0.7 & 0 & 0.5 & 1 & 1 & 1 & 1 & 1 \\
\hline
\end{tabular}
$t$ is the individual level

Table 1. Kandpal et al.'s (2017) original data without normalization as well as normalized process parameters, responses, and their levels 
Table 2a. Values from Table 4 of Kandpal et al. (2017) reflect the average values of MRR, TWR, SR, and $\mathrm{OV}$

\begin{tabular}{|c|c|c|c|c|}
\hline \multirow[t]{2}{*}{ Experimental trial } & \multicolumn{4}{|c|}{ Responses } \\
\hline & $\begin{array}{l}\text { Material } \\
\text { removal } \\
\text { rate }(\mathrm{MRR}), \\
\mathrm{mg} / \mathrm{min} \\
\end{array}$ & $\begin{array}{l}\text { Tool wear } \\
\text { rate (TWR), } \\
\text { mg/min }\end{array}$ & $\begin{array}{c}\text { Surface } \\
\text { roughness (SR), } \\
\mu_{\mathrm{m}}\end{array}$ & $\begin{array}{r}\text { Overcut } \\
(\mathrm{OV}), \mathrm{mm}\end{array}$ \\
\hline 1 & 19.008 & .225 & 6.44 & .204 \\
\hline 2 & 18.025 & .106 & 7.88 & .234 \\
\hline 3 & 18.367 & .041 & 7.45 & .243 \\
\hline 4 & 13.931 & .212 & 7.65 & .249 \\
\hline 5 & 14.569 & .11 & 7.5 & .257 \\
\hline 6 & 14.781 & .025 & 7.45 & .262 \\
\hline 7 & 15.507 & .187 & 7.56 & .277 \\
\hline 8 & 13.673 & .063 & 7.45 & .283 \\
\hline 9 & 15.593 & .401 & 6.44 & .323 \\
\hline 10 & 28.888 & .425 & 6.7 & .326 \\
\hline 11 & 25.333 & .302 & 6.85 & .327 \\
\hline 12 & 23.72 & .098 & 6.72 & .329 \\
\hline 13 & 29.575 & .361 & 6.7 & .33 \\
\hline 14 & 25.978 & .245 & 7.83 & .336 \\
\hline 15 & 23.2 & .118 & 7.76 & .339 \\
\hline 16 & 18.492 & .242 & 8.9 & .341 \\
\hline 17 & 17.631 & .2 & 7.83 & .344 \\
\hline 18 & 17.5 & .092 & 10.39 & .336 \\
\hline 19 & 33.629 & .387 & 8.8 & .341 \\
\hline 20 & 32.471 & .322 & 10.55 & .348 \\
\hline 21 & 33.357 & .144 & 10.58 & .352 \\
\hline 22 & 30.138 & .308 & 12.83 & .357 \\
\hline 23 & 28.75 & .265 & 9.77 & .362 \\
\hline 24 & 27.163 & .162 & 9.77 & .365 \\
\hline 25 & 24.25 & .344 & 12.83 & .37 \\
\hline 26 & 22.78 & .212 & 13.12 & .373 \\
\hline 27 & 21.49 & .167 & 13.19 & .377 \\
\hline
\end{tabular}

Table $2 b$. Average values of nine consecutive values in the runs for the responses

\begin{tabular}{|l|c|c|c|c|c|}
\hline \multicolumn{1}{|c|}{ Description } & Levels & \multicolumn{4}{|c|}{ Responses } \\
\cline { 2 - 6 } & & $\begin{array}{l}\text { Material removal } \\
\text { rate } \\
\mathrm{mg} / \mathrm{min}\end{array}$ & $\begin{array}{l}\text { Tool wear rate } \\
(\mathrm{TWR}), \\
\mathrm{mg} / \mathrm{min}\end{array}$ & $\begin{array}{l}\text { Surface roughness } \\
(\mathrm{SR}), \mu_{\mathrm{m}}\end{array}$ & $\begin{array}{l}\text { Overcut } \\
\mathrm{mm}\end{array}$ \\
\hline $\begin{array}{l}\text { Average of runs 1 to } \\
9\end{array}$ & 1 & 17.932 & 0.171 & 8.228 & 0.292 \\
\hline $\begin{array}{l}\text { Average of runs 10 } \\
\text { to 18 }\end{array}$ & 2 & 26.290 & 0.260 & 3.710 & 0.376 \\
\hline $\begin{array}{l}\text { Average of runs 19 } \\
\text { to 27 }\end{array}$ & 3 & 31.753 & 0.289 & 12.680 & 0.406 \\
\hline
\end{tabular}

Figure 1 reveals the sketch for the performance flow for the parametric and response set analyzed. The equivalent performance flow diagram is revealed in Figure 2. By applying the Present Worth formula, Equation (6):

Present worth $=-0.996(\mathrm{P} / \mathrm{A}, 0.12,1)+0.896(\mathrm{P} / \mathrm{A}, 0.12$, $2)+2.5(\mathrm{P} / \mathrm{A}, 0.12,3)$

From the table of present worth values, at $\mathrm{t}=1, \mathrm{i}=0.12$, value $=0.89286$, at $\mathrm{t}=2, \mathrm{i}=0.12$, value $=0.79719$ and at $\mathrm{t}=3, \mathrm{i}=0.12$, value $=0.71178$.
Then,

Present worth $=-0.996(0.89286)+0.896(0.79719)+$ $2.5(0.71178)=1.604$

In Figure 2, there are three active levels, namely levels 1,2 , and 3. On the upper side of the performance flow diagram, the responses are represented as having positive signs. The lower side of the diagram shows the normalized form's parametric values and are treated as harmful quantities since they are on the other side of the diagram. At level 1 , only $\mathrm{SR}_{\mathrm{n}}$ is represented at the 


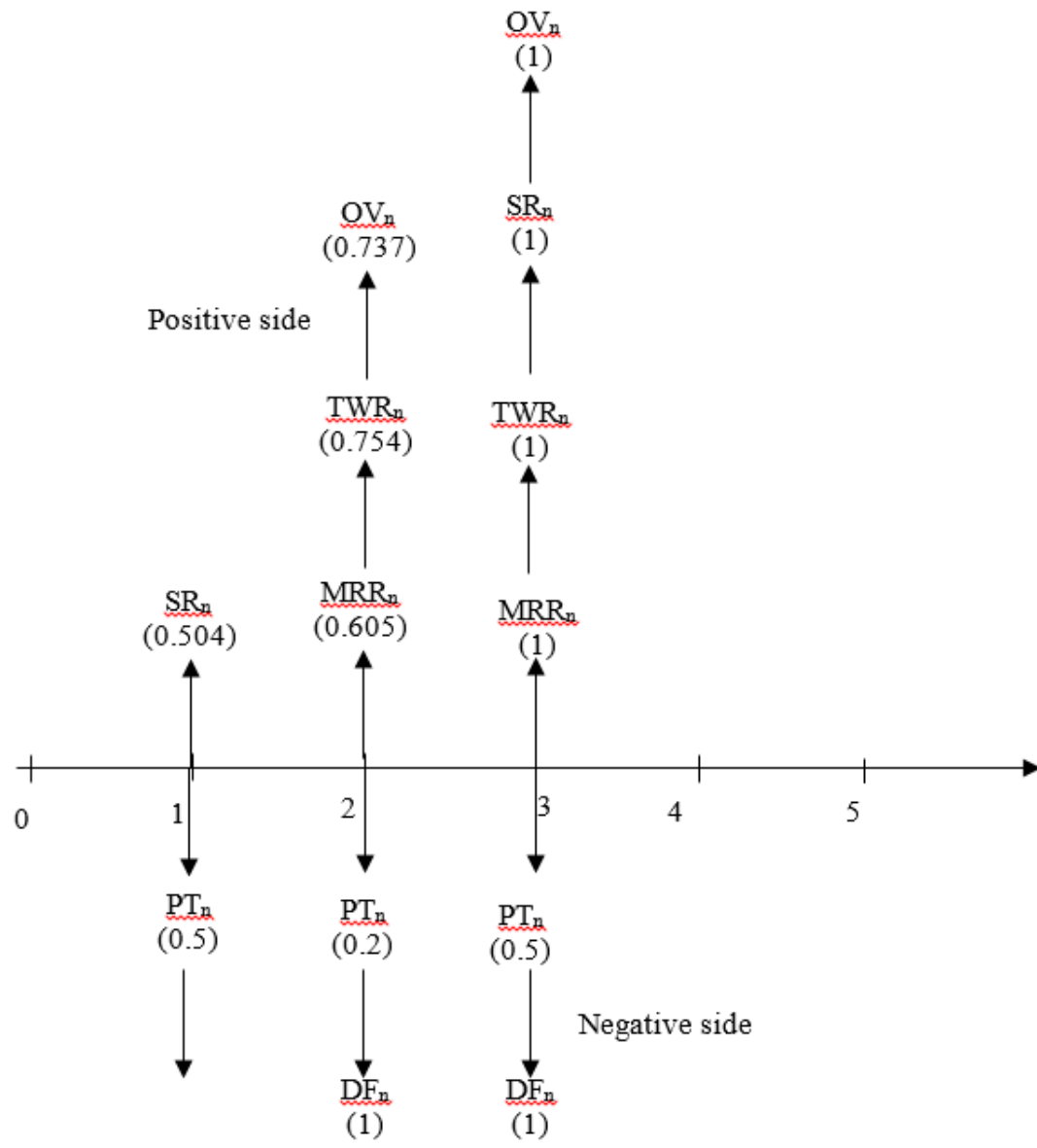

Figure 1. Present worth performance flow sketch for EDM process parameters and responses to machine AA6061/10\% $\mathrm{Al}_{2} \mathrm{O}_{3} \mathrm{AMMCs}$

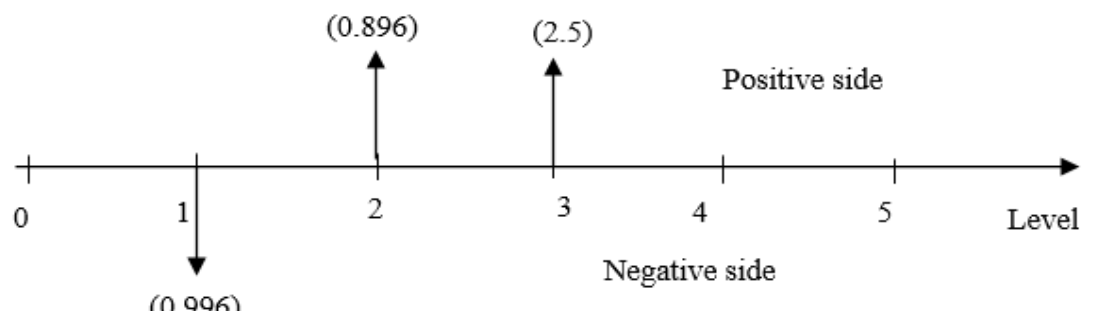

Figure 2. The equivalent present worth performance flow sketch for EDM process parameters and responses to machine $\mathrm{AA} 6061 / 10 \% \mathrm{Al}_{2} \mathrm{O}_{3} \mathrm{AMMCs}$

response side, and the value is 0.504 . On the parametric side, two parameters, $\mathrm{PT}_{\mathrm{n}}$ and $\mathrm{DF}_{\mathrm{n}}$, are represented having individual values of 0.5 and 1 , respectively. Their collective value is 1.5 . At level 2 , three responses, $\mathrm{MRR}_{\mathrm{n}}, \mathrm{TWR}_{\mathrm{n}}$, and $\mathrm{OV}_{\mathrm{n}}$, are represented on the positive side with values of $0.605,0.754$, and 0.737 , respectively, and have the sum of 2.096. On the negative side, two quantities are represented, notably $\mathrm{PT}_{\mathrm{n}}$ and $\mathrm{DF}_{\mathrm{n}}$, with individual values of 0.2 and 1 , respectively, and a collective value of 1.2. For level 3, on the positive side, the highest number of responses coinciding at a point for this problem is revealed. The responses are $\mathrm{OV}_{\mathrm{n}}, \mathrm{SR}_{\mathrm{n}}$, $\mathrm{TWR}_{\mathrm{n}}$, and $\mathrm{MRR}_{\mathrm{n}}$ with the corresponding values of $1,1,1$ and 1 . The sum of the values is 4 . On the negative side, two parameters are involved, notably $\mathrm{PT}_{\mathrm{n}}$ and $\mathrm{DF}_{\mathrm{n}}$ with values of 0.5 and 1 , respectively. The sum of the two parametric values is 1.5 .

Figure 2 is the equivalent performance flow diagram. In the conventional cash flow theory, monetary values are used instead of the line diagram's normalized values. Also, the level in the context of EDM process parameters has replaced the time traditionally used on the $\mathrm{X}$-axis of the line diagram. By applying Equation (6) to the EDM process parametric and response evaluation, each level has netted values as the compounding factor's coefficient. For instance, the first compounding factor's coefficient was obtained as 0.996 but assigned a negative value since the netted is noted and netted against the sum of the total values for the parameters at each level. For level 1, the upper side value of 0.504 is 
netted against the lower side value of 1.5 to produce a netted figure of 0.996. At level 2, the value of the upper side of 2.096 is netted against that in the lower side of 1.2 to obtain 0.896 pointing in the upward direction. Not that the final value of the netted figure of 0.966 points in the lower direction. For level 3, the upward value of 4 is netted against the low value of 1.5 to produce a final value of 2.5 in the upward direction. The new knowledge displayed here is the adoption of the cash flow value is on the negative side. The compounding factor for the first part of the workings above (P/A, 0.12, 1) shows that the present with a table is looked at with the $12 \%$ interest table while the number level is taken as 1. The value from the table is 0.89286 . Thus $0.996(0.89286)$ is the value of the first part of the equation. Similarly, other parts are computed are a final value of 1.604 is obtained. This reveals the system as being healthy as the value obtained is positive.

Table 3 may be transferred to a new table by replacing the crisps numbers as $(1,1,1),(2,3,4),(3,4,5)$, and $(4,5,6)$, respectively. Furthermore, the decimals 0.33 , 0.2 , and 0.25 are first transformed into improper fractions like $1 / 3,1 / 5$, and $1 / 4$. These numbers, $1 / 3,1 / 5$, and $1 / 4$, are further transformed into fuzzy numbers using Equation's expression (2). The understanding from Equation (2) is that the three reciprocals $1 / 3,1 / 5$, and $1 / 4$ have corresponding transformations of $(1 / 4,1 / 3,1 / 2), \quad(1 / 6,1 / 5,1 / 4), \quad$ and $(1 / 5,1 / 4,1 / 3)$, respectively. So, in the following table, the values for $1 / 3,1 / 5$, and $1 / 4$ are replaced with $(1 / 4,1 / 3,1 / 2),(1 / 6$, $1 / 5,1 / 4)$, and $(1 / 5,1 / 4,1 / 3)$, respectively.

Table 3. Design matrix for the factors (Raji and Oke, 2020)

\begin{tabular}{|l|c|c|c|}
\hline Description & $\begin{array}{c}\text { PC: Peak } \\
\text { current }\end{array}$ & $\begin{array}{c}\text { PT: Pulse } \\
\text { on time }\end{array}$ & $\begin{array}{c}\text { DF: Duty } \\
\text { factor }\end{array}$ \\
\hline $\begin{array}{l}\text { PC: Peak } \\
\text { current }\end{array}$ & 1 & 0.33 & 0.20 \\
\hline $\begin{array}{l}\text { PT: Pulse on } \\
\text { time }\end{array}$ & 3 & 1 & 0.25 \\
\hline $\begin{array}{l}\text { DF: Duty } \\
\text { factor }\end{array}$ & 5 & 4 & 1 \\
\hline
\end{tabular}

Table 4 gives the fuzzified pair, use a comparative matrix. In this paper, the fuzzy AHP proposed by Buckley in 1985 is used in which the geometric mean is used to calculate the weights (Afolayan et al., 2020; Li et al., 2020; Yazdi et al., 2020). The next issue is to compute the fuzzy geometric mean to evaluate using extent analysis (Table 5). The appropriate formula to calculate the synthetic extent concerning $1^{\text {th }}$ alternative is in Equation (7). To start with, the term A can be computed first to give $(1.4167,1.533,1.7500)$ for peak current, $(3.200,4.2500,5.3333)$ for the pulse on time, and $(8,10,12)$ for duty factor, respectively.

$$
\begin{aligned}
\tilde{\tilde{T}}^{-1}= & (g, h, k)^{-1}=\left(\frac{1}{k}, \frac{1}{h}, \frac{1}{g}\right) \\
\tilde{T}_{1} \otimes \tilde{T}_{2} & =\left(g_{1}, h_{1}, k_{1}\right) \otimes\left(g_{2}, h_{2}, k_{2}\right) \\
& =\left(g_{1} * g_{2}, h_{1} * h_{2}, k_{1} * k_{2}\right)
\end{aligned}
$$

Where $\tilde{T}_{1}$ and $\tilde{T}_{2}$ are two different fuzzy numbers, $\otimes$ is the multiplication sign, $g_{1}, g_{2}, h_{1}, h_{2}, k_{1}$ and $k_{2}$ are the fuzzy numbers. So, Equation (8) is used to multiply two fuzzy numbers. The first fuzzy geometric mean value for peak current is demonstrated as an example.

To obtain $\underset{p_{1}}{ }$ this, we have

${\tilde{p_{1}}}=\left((1 * 1 / 4 * 1 / 6)^{1 / 3},(1 * 1 / 3 * 1 / 5)^{1 / 3},(1 * 1 / 2 * 1 / 4)^{1 / 3}\right)=$ $(0.3504,0.4092,0.5035)$.

This is the value recorded for peak current. Similar calculations are made. Finally, we obtain $\underset{p_{2}}{\approx}$ and $\underset{p_{3}}{\approx}$ as $(0.7391,0.9094,1.0996)$ and $(2.2705,2.6874,3.0722)$, respectively. Next, the fuzzy weight for every criterion is calculated using Equation (9)

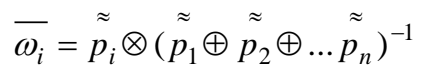

The center of the area, $w_{i}=(g+h+k) / 3$, is used to transform the fuzzy weights to weights of criteria.

Total weight of all criteria $\mathrm{x}$ total value of present worth $=1.6629$. As this number is apportioned among the parameters, the values are maintained.

\section{RESULT AND DISCUSSION}

There is an increasing need to develop models or frameworks to select EDM process parameters for resource-sharing decisions. In the EDM process operation, difficulties predominantly occur when the process engineer distributes material resources and assigns operators to different machine terminals. The process engineer at this point is without scientific tools

\begin{tabular}{|c|c|c|c|c|c|c|}
\hline Description & $\begin{array}{l}\text { PC: } \\
\text { Peak } \\
\text { current }\end{array}$ & $\begin{array}{l}\text { PT: Pulse on } \\
\text { time }\end{array}$ & $\begin{array}{l}\text { DF: Duty } \\
\text { Factor }\end{array}$ & $\begin{array}{c}\text { Fuzzy geometric mean } \\
\approx \\
\text { values, } \tilde{p}_{i}\end{array}$ & Fuzzy weights, $\overline{w_{i}}$ & $\begin{array}{c}\text { Weight, } \\
w_{i}\end{array}$ \\
\hline $\begin{array}{l}\text { PC: Peak } \\
\text { current }\end{array}$ & $(1,1,1)$ & $(1 / 4,1 / 3,1 / 2)$ & $(1 / 6,1 / 5,1 / 4)$ & $(0.3504,0.4092,0.5035)$ & $(0.0749,0.1021,0.1499)$ & 0.1089 \\
\hline $\begin{array}{l}\text { PT: Pulse } \\
\text { on time }\end{array}$ & $(2,3,4)$ & $(1,1,1)$ & $(1 / 5,1 / 4,1 / 3)$ & $(0.7391,0.9094,1.0996)$ & $(0.1581,0.2270,0.3273)$ & 0.2375 \\
\hline $\begin{array}{l}\text { DF: Duty } \\
\text { factor }\end{array}$ & $(4,5,6)$ & $(3,4,5)$ & $(1,1,1)$ & $(2.2705,2.6874,3.0722)$ & $(0.4856,0.6708,0.9143)$ & 0.6903 \\
\hline
\end{tabular}
to guide decisions but intuition and experience. To

Table 4. Fuzzified design matrix for the EDM parameters 
Table 5. Weight computation for the parameters of the EDM process

\begin{tabular}{|c|c|c|c|}
\hline Description & Weights, $w_{i}$ & $\begin{array}{c}\text { Fuzzy normalized } \\
\text { weights }\end{array}$ & $\begin{array}{c}\text { Present worth normalized } \\
\text { weights }\end{array}$ \\
\hline PC: Peak current & 0.1089 & 0.1051 & 0.1051 \\
\hline PT: Pulse on time & 0.2375 & 0.2290 & 0.2290 \\
\hline DF: Duty factor & 0.6903 & 0.6658 & 0.6658 \\
\hline Total & 1.0367 & 1.0000 & 1.0000 \\
\hline
\end{tabular}

compound the process engineer's challenge, the process engineer's values in judgments of tasks and attributes of resources are uncertain. This arises from ambiguity and imprecision, among others.

Furthermore, the process engineer is under constant pressure from the trade union on demands for incentives. Thus, in reality, the process engineer stands the chances of failures if intuition fails and the company is at risk of profit losses and inferior quality products. Therefore, it is crucial to analyze the uncertainty situation that prevails in the choice of parameters for machining the work material, AA6061/10\% $\mathrm{Al}_{2} \mathrm{O}_{3} \mathrm{AMMCs}$. This will enable the process engineer to appraise the parameters of the EDM process better. This article aims to develop a fuzzy analytical hierarchy framework for selecting EDM parameters under uncertain conditions, with some considerations of economic terms to enhance the distribution scheme robustness of resources by identifying the best parameter in the EDM process. This paper's non-deterministic approach involves introducing fuzzy normalized weights according to the computation of the geometric mean approach to fuzzy AHP modeling. It also involves developing a fuzzified pairwise comparison matrix and introducing a degree of possibility in the extent analysis approach to fuzzy AHP modeling. It is proposed that the numbers treated as crisp, assuming a deterministic framework are not so. It is non-deterministic and contains substantial uncertainty. The two approaches to fuzzy AHP modeling have been compared with the experimental data regarding the work material AA6061/10\% $\mathrm{Al}_{2} \mathrm{O}_{3} \mathrm{AMMCs}$.

\section{The rationale for the methodology and procedure}

The Al6061, a heat-treatable aluminum alloy, is widely used for industrial use. The $\mathrm{Al} 6061 / 10 \% \mathrm{Al}_{2} \mathrm{O}_{3} \mathrm{AMMCs}$ is the treated version of the Al6061 with potentials for use in the construction industry with broad appeal in the production of automotive sub-assemblies. They are also preferred for bicycle frames, yacht development, tank building, couplings/values, camera lenses, electrical fittings, motorcycles, and fishing reels. Selecting the EDM process parameters during the machining of $\mathrm{Al} 6061 / 10 \% \mathrm{Al}_{2} \mathrm{O}_{3} \mathrm{AMMCs}$ manufactured using the stir casting method using the electrical discharge machine encourages discrimination in resource sharing. This offers informed reactions to the resource needs imposed by the processes influencing efficiency, machining economics, and machined products' quality. In this paper, Kandpal et al.'s (2017) paper that focused on the characterization of the $\mathrm{Al} 6061 / 10 \% \mathrm{Al}_{2} \mathrm{O}_{3} \mathrm{AMMCs}$ is considered to discuss a new theme for value-added research to the EDM community.

It is argued that although quality processes material on EDM may be achieved using Kandpal et al., (2017) approach, new insights reveal that the economics of sharing resources through discriminatory parametric analysis would solve this wasteful approach of not identify the most critical parameters to direct decision on resource sharing. To this end, the use of a multicriteria model of the analytical hierarchy process may be attempted. The selection problem involves considering how many resources to allocate to activities associated with the pulse on time, duty factor, and peak current. At the same time, the responses are considered as the overcut material removal rate and surface roughness. For instance, how much labor hours, machine hours, material space consideration for workpiece is needed for optimum practice? Too much of any of these factors deprive other factors and hence attested to the system's performance. This is a multi-criteria decision-making problem since the criteria/ factors are conflicting.

From the earlier discussion, it is argued that the analytical hierarchy process may be a choice in the selection process. However, the process engineer cannot adequately quantify the usage of these factors with changes in times. For instance, the engineer does not have control over the lead time to supply the dielectric material for use in the system. This depends on the accounting, logistics, and top management's decision to release funds and when directives are given to the supplier to deliver the dielectric material. This makes the situation challenging with uncertainties and imprecision in judgment. Thus, instead of using the multi-criteria in model of analytical hierarchy process to solve this problem, it could be solved by using the fuzzy analytical hierarchy process (FAHP), thus, taking this direction, this paper employs the FAHP to confront the selection process for the EDM process of $\mathrm{Al} 6061 / 10 \% \mathrm{Al}_{2} \mathrm{O}_{3} \mathrm{AMMCs}$. It uses the experiment data of $\mathrm{Al} 6061 / 10 \% \mathrm{Al}_{2} \mathrm{O}_{3} \mathrm{AMMCs}$ to verify the FAHP model presented in this work.

The steps taken in this section are as follows:

Step 1: Extract the data on Peak current, Pulse on time, and Duty factor from Kandpal et al. (2017), shown as Table 2, page 358 in the original work.

In this paper's context, a membership function is a structure that describes the complete information about a fuzzy set modeling of the electrical discharge machining parametric selection process for resource distributive effectiveness (Table 6 and Figure 3). The 
membership function may be easily understood by considering its distinctive characteristics by the terms they are referred to. First, it is essential to note that a membership function for the fuzzy set EDM on the universe discourse containing elements PT, PC, and DF, representing the pulse on time, peak current, and duty factor, respectively, may be expressed mathematically as $\mu_{E D M_{\text {total }}} \rightarrow[0,1]$, such that the elements of $E D M_{\text {total }}$ are mapped to a value ranging from 0 to 1 . This value is referred to as the membership or membership value level and specifies the level of membership of the element in $E D M_{\text {total }}$ to the fuzzy set $E D M$. With a case, membership functions are used to reveal a fuzzy set graphically. The graph, which contains the $x$ and $y$ axes, shows the universe of discourse and membership level, correspondingly. The interval of analysis is, however, from 0 to 1 . Boundary, core, and support are the key terms that describe the fuzzy set's membership functions. These features are best described using the trapezoidal membership functions where the boundaries are each represented on the longest line, shared by the support feature. On the shorter side of the $x$-axis lies the cone. More technically defined, a boundary for some fuzzy set $E D M \sim$ is defined as the part of the universe holding the elements that contain non-zero membership. However, it is not a total membership.
Zadeh laid the foundation for membership function structuring and definitions. There are two principal categories of membership functions. These are the nonlinear category: the following are the principal representatives: Gaussian function and gamma function. The linear category is the second type and represented by the singleton function, trapezoidal function of the " $\mathrm{L}$ " class (or "L" function), the trapezoidal function of the "R" class (or the "R" function), triangular function, trapezoidal function and extended trapezoidal function. In practice, it was discovered that the computational time for the non-linear function (i.e., Gaussian) is high and not affordable to the practicing process engineer in charge of the EDM process. Hence, the non-linear function has not been the literature's patronage, and the linear functions are the most commonly used. In the literature on fuzzy logic, it is often stated that many researchers have considered the trapezoidal function on the merit of being adaptable quite well to different sets of problems, claiming that it is straightforward in definition and representation. It is easy to compute. In some complicated problems, the extended trapezoidal functions have been found useful. However, the literature cautions that precision is not necessarily achieved using more complicated functions since the idea being worked on is fuzzy.

Table 6: The 9-point scale of Thomas Saaty (Saaty, 2008; Onyegiri and Oke, 2016)

\begin{tabular}{|c|l|l|}
\hline $\begin{array}{c}\text { Magnitude of } \\
\text { intensity }\end{array}$ & \multicolumn{1}{|c|}{ How is it described? } & \multicolumn{1}{|c|}{ Particulars } \\
\hline 1 & Identical importance & A pair of parameters add likewise to the objective \\
\hline 2 & Weak or slight & - \\
\hline 3 & Modest importance respect a \\
\hline 4 & Modest plus & $\begin{array}{l}\text { Experience and review weakly } \\
\text { parameter above the other }\end{array}$ \\
\hline 5 & Vigorous importance & - \\
\hline 6 & Vigorous plus & $\begin{array}{l}\text { Experience and review vigorously respect a } \\
\text { parameter above the other }\end{array}$ \\
\hline 7 & $\begin{array}{l}\text { Extremely vigorous or instituted } \\
\text { importance }\end{array}$ & $\begin{array}{l}\text { A parameter is extremely robustly over another; } \\
\text { its pre-eminence ascertained practically }\end{array}$ \\
\hline 8 & Extremely, Extremely vigorous & - \\
\hline 9 & Incredible importance & $\begin{array}{l}\text { The evidence esteeming one task above the other } \\
\text { has the highest classification of confirmation }\end{array}$ \\
\hline $2,4,6,8$ & Midway values & A sound supposition \\
\hline $1 / 3,1 / 5,1 / 7,1 / 9$ & Values for opposite comparison & - \\
\hline
\end{tabular}

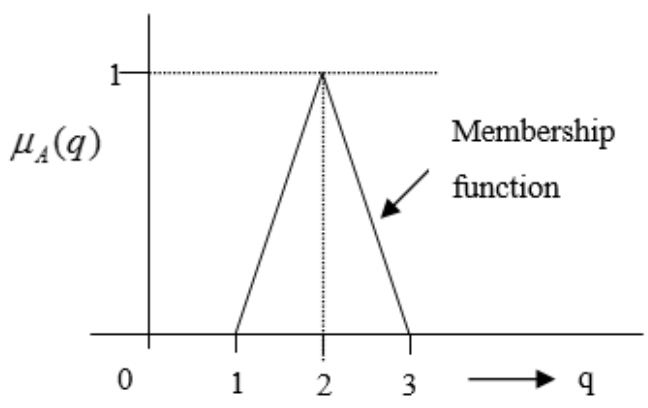

Figure 3. Triangular membership function 
K.O. Okponyia and S.A. Oke

To successfully translate the crisp numeric value into linguistic terms, the idea of fuzzification is used. It is defined as the procedure embarked upon to convert a crisp quantity to fuzzy. This is achieved by accepting that numbers treated as crisp, following deterministic analysis, are not deterministic but contain substantial uncertainty. The uncertainty may be linked to ambiguity, imprecision, or vagueness. In this case, the EDM component variables such as the pulse on time, peak current, and duty factor are likely to be fuzzy. They may be indicated as member functions in the membership function diagram. For instance, for the triangular membership function, the height is what is read to understand the degree of the membership function.

\section{Fuzzy AHP's scale of relative importance}

The scale of relative importance used in the AHP method is transformed to a fuzzy scale of relative importance and is given below:
Equal
$(1,1,1)$
Moderate
Strong
Very Strong
Extremely Strong
Intermediate values $\quad(1,2,3)(3,4,5)(5,6,7)(7,8,9)$

The fuzzy scale of relative importance solves the ordinary scale's limitations, which do not account for values in between the different criteria (Table 7). For example, values are like $2.5,3.5$, and so on.

The values are then changed to their corresponding fuzzy numbers, and transformation is done (Table 8).

The next step is to calculate the fuzzy geometric mean $\approx$

(Table 9), $\approx r_{i}$ which Buckley proposed in 1985.

The fuzzy weights are then calculated using the formula: $\underset{w_{i}}{\approx}=\underset{r_{i}}{\approx} \approx\left(\underset{r_{1}}{\approx} \approx \underset{r_{2}}{\approx} \approx r_{3}\right)^{-1}$

where $\tilde{r_{1}} \otimes \underset{r_{2}}{\approx} \otimes \underset{r_{3}}{\approx}=(2.8077,3.7046,4.7081)$

Therefore,

$\left(\tilde{r_{1}} \otimes \underset{r_{2}}{\approx} \approx \widetilde{r_{3}}\right)^{-1}=\left(\frac{1}{4.7081}, \frac{1}{3.7046}, \frac{1}{2.8077}\right)$

To defuzzify (Table 10) the weights to get the numerical values of the fuzzified weights, the Centre of Area method is used, which is given as $w_{i}=(1+\mathrm{m}+\mathrm{u}) / 3$.

The sum of the numerical weights equals 1.0911, which is not accepted. The accepted value is 1 . These weights, therefore, have to be normalized (Table 11). The sum of the numerical weights equals 1.0911, which is not acceptable as it is above 1 . Thus, computation is made to normalize the weights (Table 11). To obtain the first entry under the normalized weights, 0.32 , the value under $w_{i}$, which is 0.3533 , is divided by the sum of all values of $w_{i}$, which is 1.0911 . The values for the pulse on time, duty factor are obtained as 0.57 and 0.11 , respectively. It is noted that by summing all the normalized weights, a value of 1 is therefore obtained.

The normalized weights in Table 11 are the rescaled translation of the numerical weights obtained from the deployment of both the present worth method and the fuzzy analytical hierarchy to the Kandpal et al.'s (2017) published data. The normalized weights are related to the determination of the most important parameter. It acknowledges the pulse on time as the most important parameter, followed by the peak current, while the least important parameter is the duty factor. Regarding the distribution of resources, if a shared resource such as energy were to be shared among the three, on the face value, $57 \%$ of the energy value should be assigned to pulse on time, $32 \%$ to peak current. In contrast, the rest, $11 \%$, should be assigned to the duty factor. However, in

Table 7. Pair-wise comparison matrix

\begin{tabular}{|l|l|l|l|}
\hline Factors & Peak current & Pulse on time & Duty factor \\
\hline Peak current & 1 & $\mathrm{x} / 2 \mathrm{x}=1 / 2$ & $3 \mathrm{x} / \mathrm{x}=3$ \\
\hline Pulse on time & $2 \mathrm{x} / \mathrm{x}=2$ & 1 & $5 \mathrm{x} / \mathrm{x}=5$ \\
\hline Duty factor & $\mathrm{x} / 3 \mathrm{x}=1 / 3$ & $\mathrm{x} / 5 \mathrm{x}=1 / 5$ & 1 \\
\hline
\end{tabular}

Table 8. Transformation of pair-wise comparison matrix to fuzzy numbers and calculation of fuzzy geometric

\begin{tabular}{|l|l|l|l|l|}
\hline Factors & Peak current & Pulse on time & Duty factor & $\approx$ \\
\hline Peak current & $(1,1,1)$ & $(1 / 3,1 / 2,1 / 1)$ & $(2,3,4)$ & $(0.8736,1.1447,1.5874)$ \\
\hline Pulse on time & $(1,2,3)$ & $(1,1,1)$ & $(4,5,6)$ & $(1.5874,2.1544,2.6207)$ \\
\hline Duty factor & $(1 / 4,1 / 3,1 / 2)$ & $(1 / 6,1 / 5,1 / 4)$ & $(1,1,1)$ & $(0.3467,0.4055,0.5)$ \\
\hline
\end{tabular}

Table 9. Fuzzy weights $\underset{w_{i}}{ }$

\begin{tabular}{|l|c|c|}
\hline Factors & $\approx$ & $\approx$ \\
& $r_{i}$ & $\tilde{w}_{i}$ \\
\hline Peak current & $(0.8736,1.1447,1.5874)$ & $(0.1856,0.309,0.5654)$ \\
\hline Pulse on time & $(1.5874,2.1544,2.6207)$ & $(0.3372,0.5815,0.9334)$ \\
\hline Duty factor & $(0.3467,0.4055,0.5)$ & $(0.0736,0.1095,0.1781)$ \\
\hline
\end{tabular}


practice, the process engineer may use discretion to adjust these values suitably according to some other input parameters that may influence the machine or system performance beyond the analysis given here. Such may include the machine's age, the workers' skill level, and their work availability. Compared to the results of Kandpal et al. (2017), while our study focused on selecting the critical parameter, this benchmarked study only considered the optimization of the parameters. Such an optimization process led to the evaluation of optimal parametric quantities and predicted optimal values for the responses: material removal rate $\left(A_{3} B_{1} C_{1}\right.$ and 32.788), tool wear rate $\left(A_{I} B_{I}\right.$ $\mathrm{C}_{I}$ and 0.2520), surface roughness $\left(\mathrm{A}_{1} \mathrm{~B}_{1} \mathrm{C}_{1}\right.$ and $6.472 \mathrm{~mm})$, and overcut $\left(\mathrm{A}_{1} \mathrm{~B}_{1} \mathrm{C}_{1}\right.$ and $\left.0.234 \mathrm{~mm}\right)$. However, it is possible to compare the obtained results with a previous study by Raji and Oke (2020).

In the benchmark study by Raji and Oke (2020), the optimization of the parameters was accomplished while the analytical hierarchy process was used to determine weights (Table 12). The comparison revealed a considerable variation between the results given by AHP and FAHP. This conflict is understandable because the AHP is weak in capturing the uncertainty, which is highly pronounced and revealed when the FAHP was applied together with the economic factor, on the original Kandpal et al.'s (2017) data. In the current study, the pulse on time was given the most important parameter in the system. However, contrarily, the duty factor attained the position while the AHP method was applied. Surprisingly, this best factor was assigned as the worst factor in our study. The explanation is that it is less sensitive to uncertainty and hence marginally affected by the combined effects of economics and the FAHP. Regarding the differences in percentage, it was huge for duty factor (504.64\%) and less substantial for the peak current $(-67.56 \%)$ and pulse on time $(-59.46 \%)$.

The optimized membership functions are shown in Figures 4, 5, and 6, while the decision tree image is shown in Figure 7.

Although the electrical discharge machining (EDM) field has been active for decades, the present authors envisage a new development of the field. It is envisioned that EDM scholarship should have practitioners positioned at the intersection of several fields, including production, mechanics, heat transfer, and engineering economics. This creates opportunities for EDM researchers to understand these research areas, integrate them with experimental data and simulation, and propose theories that could probably assist researchers in garnering a total understanding of the desired EDM phenomenon. This paper chooses to develop a framework to help explain the economic aspects of EDM operations, linking the idea of present worth to workers' performance in the EDM factory floor in an assessment of the plant's sustainability. The paper's goal was to go beyond the technical, operational aspects such as assessing the EDM parameters of pulse ON time, pulse OFF time, duty current, and so on, to link the interest rate of borrowed funds, which may be dynamic over time. This extends previous studies that suggest the economic aspect as a single influential factor of an EDM plant's performance but has demonstrated an absymal interface with the will ultimately be established by further experimental and simulation analysis. It is anticipated that engineering economics scholars will explore this aspect that may play a significant role in the employment and retention of EDM engineers and operators in the industry.

Table 10. Defuzzied weights

\begin{tabular}{|c|c|}
\hline$\approx$ & Weight, $w_{i}$ \\
\hline$w_{i}$ & \\
\hline$(0.1856,0.309,0.5654)$ & 0.3533 \\
\hline$(0.3372,0.5815,0.9334)$ & 0.6174 \\
\hline$(0.0736,0.1095,0.1781)$ & 0.1204 \\
\hline Total & 1.0911 \\
\hline
\end{tabular}

Table 11: Normalized weights for FAHP method

\begin{tabular}{|l|c|c|}
\hline Factors & $w_{i}$ & $\begin{array}{c}\text { Normalized } \\
\text { Weights }\end{array}$ \\
\hline Peak current & 0.3533 & 0.32 \\
\hline Pulse on time & 0.6174 & 0.57 \\
\hline Duty factor & 0.1204 & 0.11 \\
\hline Total & 1.0911 & 1.000 \\
\hline
\end{tabular}

Table 12: Compared results of AHP and FAHP methods

\begin{tabular}{|l|c|c|c|}
\hline Factors & AHP (Raji and Oke, 2020) & FAHP (Current study) & $\%$ Differences \\
\hline Peak current (PC) & 0.1038 & 0.32 & -67.56 \\
\hline Pulse on time (PT) & 0.2311 & 0.57 & -59.46 \\
\hline Duty factor (DF) & 0.6651 & 0.11 & 504.64 \\
\hline Total & 1.000 & 1.000 & \\
\hline
\end{tabular}




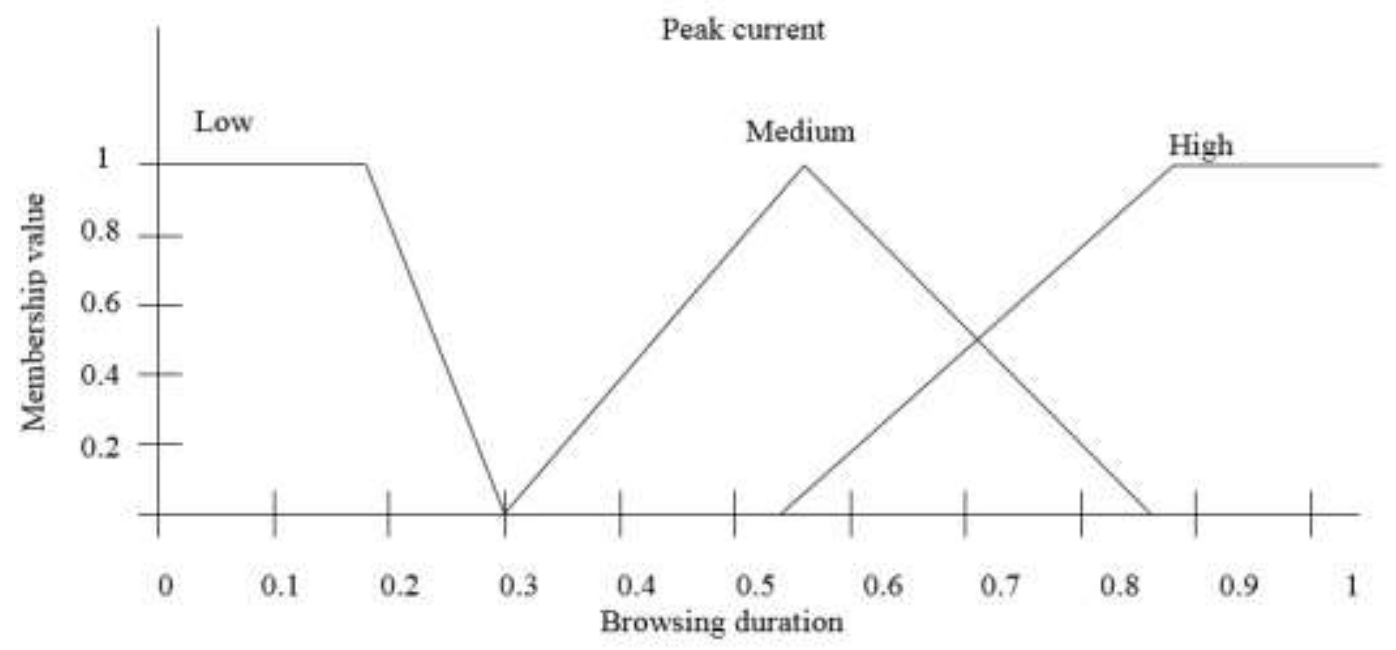

Figure 4. Optimized membership function (Peak current)

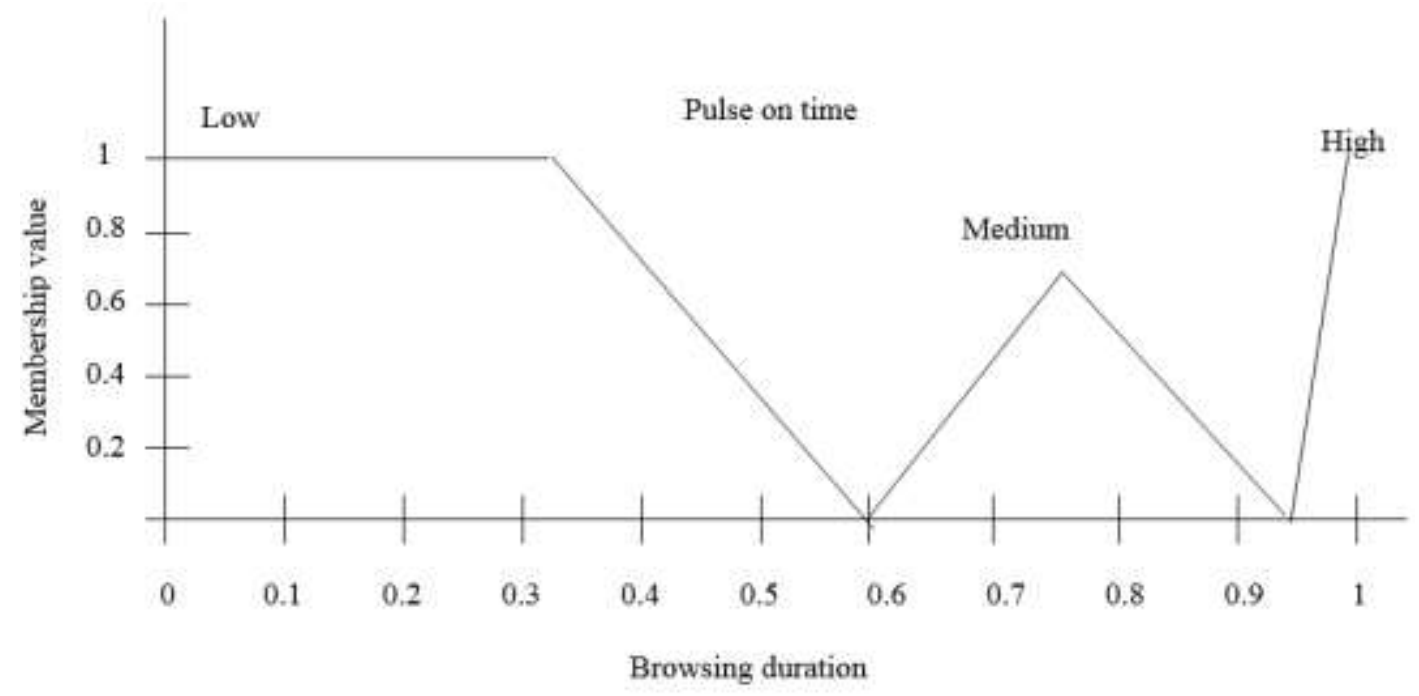

Figure 5. Optimized membership function (Pulse on time)

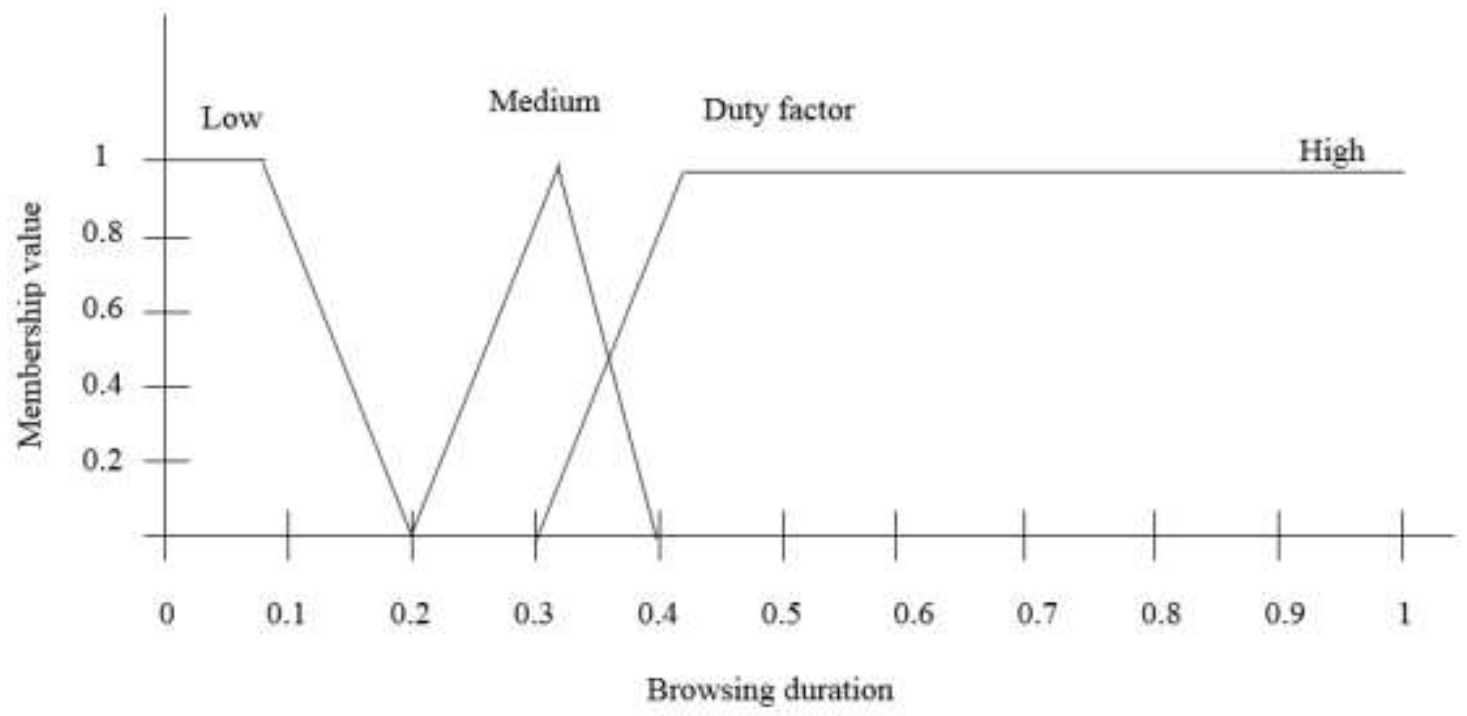

Figure 6. Optimized membership function (Duty factor) 

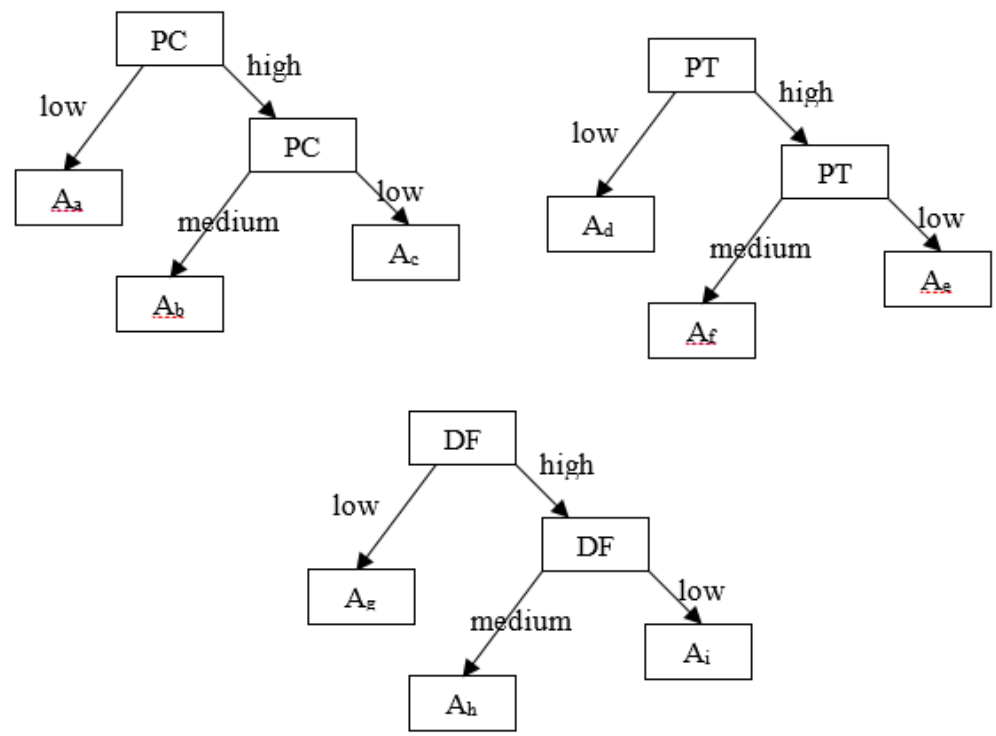

Note: $A_{a}$ to $A_{g}$ are terminal elements of the decision

Figure 7. Decision tree image

\section{CONCLUSIONS}

Process characteristics selections such as parametric selection in electrical discharge machining systems are always essential in diverse companies, whether private or public. This is because resources are limited, and the process engineer must ensure that they are adequately distributed. Nonetheless, it is known that such distribution practices in industries, at present, are achieved at sub-optimal levels. Thus, this study aims to install a procedure to select the best parameters in an EDM process while machining the work material, AA6061/10\% $\mathrm{Al}_{2} \mathrm{O}_{3} \mathrm{AMMCs}$, based on the fuzzy AHP method. This paper's principal focus is to select the most important parameter that produces the optimum EDM responses in a machining process. A new model is proposed to attain the work's goal, the fuzzy analytical hierarchy process that captures uncertainty and imprecision in the EDM process parameters. The parametric study involved experimental data from the literature, due to Kandpal et al. (2017), and the work material is $\mathrm{Al} 606 \mathrm{l} / 10 \% \mathrm{Al}_{2} \mathrm{O}_{3}$ AMMCs. The FAHP is an advancement of the AHP with which fuzzy theory has been added.

The following conclusions are valid:

1. The present worth method, fuzzy analytical hierarchy process method using the fuzzy geometric mean approach, and the fuzzy analytical hierarchy process using the extent analysis approach have been affirmed to be feasible to apply an electrical discharge machining. Experimental data from the literature, Kandpal et al. (2017) validated the approaches. The present worth method yielded a value of 1.604 , a positive number indicating that the system is healthy. Thus, the present worth method could be used as a diagnostic tool. It reveals a healthy EDM process in machining AA6061/10\% $\mathrm{Al}_{2} \mathrm{O}_{3} \mathrm{AMMCs}$ when the overall sign is positive and unhealthiness when negative. For negative signs, further tools such as cause and effect analysis and 5Whys may be used for a more detailed understanding of the system.

2. The peak current was found to have the highest ratio of the three parameters and should be given the utmost importance during the implementation of EDM machining of AA6061/10\% $\mathrm{Al}_{2} \mathrm{O}_{3} \mathrm{AMMCs}$.

3. During the machining of the workpiece, AA6061/10\% $\mathrm{Al}_{2} \mathrm{O}_{3}$ AMMCs, resources could be distributed in the ratio of $\mathrm{A}<\mathrm{B}$ and $\mathrm{C}$ regarding peak current, pulse on time, and duty factor. However, further analysis is needed to determine more detailed resource sharing information to the parameters during the work material's EDM processing.

4. The fuzzy AHP with geometric mean and the fuzzy AHP with extent analysis proceed to convert qualitative EDM process parametric information into quantitative information capable of assisting the process engineer in decision making. The center of area method was valid in transforming the parametric values' fuzzy weights for the EDM process into weights having crisp numeric values.

Symbols and abbreviations

Symbols

$\approx$

$r_{i} \quad$ the fuzzy geometric mean for the $\mathrm{i}^{\text {th }}$ term

$\approx$

$w_{i} \quad$ fuzzy weights for the $\mathrm{i}^{\text {th }}$ term

$Q_{\text {latest }}$ latest value obtained from the conversion exercise

$Q \quad$ value of the data to be transformed into a normalized form

$Q_{\min } \quad$ minimum value obtained from the array of numbers considered

$Q_{\max } \quad$ maximum value obtained from the array of numbers considered

$i \quad$ interest rate 
K.O. Okponyia and S.A. Oke

$\begin{array}{ll}t & \text { individual level } \\ \text { Abbreviations } & \\ \text { OV } & \text { overcut } \\ \text { SR } & \text { surface roughness } \\ \text { MRR } & \text { material removal rate } \\ \text { TWR } & \text { tool wear rate } \\ \text { FAHP } & \text { fuzzy analytical hierarchy process } \\ \text { AHP } & \text { analytical hierarchy process } \\ \text { PWFAHP } & \text { present-worth-assisted fuzzy analytical } \\ & \text { hierarchy process } \\ \text { PC } & \text { normalized value for peak current } \\ \text { PT } & \text { normalized value for the pulse on time } \\ \text { DF } & \text { normalized value for duty factor } \\ \text { MRR }_{n} & \text { normalized value for material removal } \\ & \text { rate } \\ \mathrm{TWR}_{\mathrm{n}} & \text { normalized value for tool wear rate } \\ \mathrm{SR}_{\mathrm{n}} & \text { normalized value for surface roughness } \\ \mathrm{OV}_{\mathrm{n}} & \text { normalized value for overcutting }\end{array}$

\section{REFERENCES}

Afolayan A.H., Ojokoh B.A., Adetunmbi A.O. 2020. Performance analysis of fuzzy analytic hierarchy process multi-criteria decision support models for contractor selection, Scientific African, 9, 1-22.

Asilturk, I., Cunkas, M, 2010. Modeling and prediction of surface roughness in turning operations using artificial neural network and multiple regression method, Expert Systems with Applications, 38, 58265832 .

Boussabaine A.H. and Elhag T., 1999, Applying fuzzy techniques to cash flow analysis, Construction Management and Economics, 17(6), 745-755.

Chen, Y., Mahdivian, S.M., 2000. Analysis of electrodischarge machining process and its comparision with experiments, Journal of Materials Processing Technology, 104, 150-157.

Chiang, K., 2008. Modeling and analysis of the effects of machining parameters on the performance characteristics in the EDM process of $\mathrm{Al}_{2} \mathrm{O}_{3}+\mathrm{TiC}$ mixed ceramic, International Journal of Advanced Manufacturing Technology, 37, 523-533.

Chiu C-Y and Park C.S, 1994. Fuzzy cash flow analysis using present worth criterion. The Engineering Economist, 39(2), 113-138.

Chockalingam K., Jawahar N., Muralidharan N., Jeyaraj K.L. 2019. Material subtraction study of AISI T-15HSS by wire cut electrical discharge machining (CNCwire cut EDM) based on Taguchi grey relational analysis, International Journal of Machining and Machinability of Materials, 21(3), 139-168.

Das M.K., Kumar K., Barman T.K., Sahoo P. 2014, Application of artificial bee colony algorithm for optimization of MRR and surface roughness in EDM of EN31 tool steel, Procedia Materials Science, 6,
741-751.

Das, M.K., Kumar, K., Barman, T.K., Sahoo, P., 2013. Optimization of surface roughness and MRR in EDM using WPCA. Procedia Engineering, 64, 446-455.

Dewangan S., Kumar S.D., Jha S.K., Biswas C.K. 2020, Optimization of Micro-EDM drilling parameters of Ti-6Al-4V alloy, Materials Today: Proceedings, 3, $1-5$.

Doss D.A., Jones D.W., Sumrall W, Henley R., McErneath D., Lackey H., Gokaraju B., 2015, a net present worth analysis of considered academic programs at a private regional higher educational institution, Journal of Interdisciplinary Studies in Education, 4(1), 55-77.

Fazlollahtabar H., Gholizadeh H. 2020, Fuzzy possibility regression integrated with fuzzy adaptive neural network for predicting and optimizing electrical discharge machining parameters, Computers \& Industrial Engineering, 140, 1-9.

Gupta V., Singh B. and Mishra R.K., 2020, Machining of titanium and titanium alloys by electric discharge machining process: a review, International Journal of Machining and Machinability of Materials, 22(2), 99121.

Ilani, M.A., Khoshnevisan, M. 2020. Powder mixedelectrical discharge machining (EDM) with the electrode is made by fused deposition modeling (FDM) at Ti-6Al-4V machining procedure. Multiscale and Multidisciplinary Modeling, Experiments and Design, 3, 173-186.

Jaharah, A., Liang, C., Wahid, A., S.Z., Rahman, M., Hassan, C.C., 2008. Performance of copper electrode in electrical discharge machining (EDM) of AISI H13 harden steel. International Journal of Mechanical and Materials Engineering, 3, 25-29.

Kuppan, P., Rajadurai, A., Narayanan, S., 2007. Influence of EDM process parameters in deep hole drilling of Inconel 718, International Journal of Advanced Manufacturing Technology, 38, 74-84.

Kanagarajan, D., Karthikeyan, R., Palanikumar, K., Sivaraj, P., 2008. Influence of process parameters on electric discharge machining of $\mathrm{WC} / 30 \% \mathrm{Co}$ composites, Proceedings of the Institution of Mechanical Engineers, Part B: Journal of Engineering Manufacture, 222, 807-815.

Kandpal B.C., Kumar J. and Singh H. 2017. Optimization and characterization of EDM of AA $6061 / 10 \% \mathrm{Al}_{2} \mathrm{O}_{3}$ AMMC using Taguchi's approach and utility concept, Production and Manufacturing Research, 5(1), 351-370.

Kandpal B.C., Kumar J., Singh H., 2018. Optimization 
of electrical discharge machining AA6061/10\% $\mathrm{Al}_{2} \mathrm{O}_{3}$ composite using Taguchi optimization technique, Materials Today: Proceedings, 5(9), 18946-18955.

Karthikeyan G., Ramkumar J., Shalabh, Aravindan S. 2012. Performance analysis of $\mu$ ED-milling process using various statistical techniques, International Journal of Machining and Machinability of Materials, 11(2), 183-203.

Lajis, M.A., Mohd Radzi H.C.D., Nurul Amin, A.K.M., 2009. The Implementation of Taguchi method on EDM process of tungsten carbide, European Journal of Scientific Research, 26, 609-617.

Li Z., Chow D.H.C., Ding D., Ying J., Hu Y., Chen H., Zhao W., 2020. The development and realisation of a multi-faceted system for green building planning: A case in Ningbo using the fuzzy analytical hierarchy process, Energy and Buildings, 226, 1-11.

Lin, Y.C., Yan, B.H., Huang, F.Y., 2001. Surface improvement using a combination of electrical discharge machining with ball burnish machining based on the Taguchi method, International Journal of Advanced Manufacturing Technology, 18, 673-682.

Mahdavinejad, R.A, 2008. Optimisation of electro discharge machining parameters, Journal of Achievement in Materials and Manufacturing Engineering, 27, 163-166.

Martínez-Alvarado R., Granda-Gutiérrez E.E., Hernández-Rodríguez A., Praga-Alejo R.J. 2020. Pulse classification for an electrochemical discharge machining process based on fuzzy logic approach. International Journal of Precision Engineering and Manufacturing, 21, 1-12.

Maravas A and Pantouvakis J-P., 2018, A new approach to studying net present value and the internal rate of return of engineering project under uncertainty of three-dimensional graphs, Advanced Management in Civil Engineering, 2018, 1-9.

Maurya R., Porwal R.K., Singh R. 2019, Concerning drifts to optimization techniques of wire-EDM process for titanium based super alloys: A review, Materials Today: Proceedings, 18(7), 4509-4514

Onyegiri I.E. and Oke S.A. 2016. An analytic hierarchical approach to building airline safety management systems, Erzincan University Journal of Science and Technology, 9(3), 147-163.

Payal, H.S., Rajesh, C., Sarabjeet, S., 2008. Analysis of electro discharge machined surfaces of EN-31 tool steel, Journal of Scientific and Industrial Research, 67, 1072-1077.

Phate M., Toney S. \& Phate V., 2020, Modelling and investigating the impact of EDM parameters on surface roughness in $\mathrm{EDM}$ of $\mathrm{Al} / \mathrm{Cu} / \mathrm{Ni}$ Alloy, Australian Journal of Mechanical Engineering, 1-14.

Pradhan,M.K., Biswas, C.K., 2008. Neuro-fuzzy model on material removal rate in electrical discharge machining in AISI D2 steel, Proceedings of the 2nd International and 23rd All India Manufacturing Technology, Design and Research Conference, 1, 469474.

Pradhan, M.K., Das, R., Biswas, C.K., 2009. Comparisons of neural network models on surface roughness in electrical discharge machining, Proceedings of the Institution of Mechanical Engineers, Part B: Journal of Engineering Manufacture, 223, 801-808.

Puertas, I., Luis, C.J., Alvarez, L., 2004. Analysis of the influence of EDM parameters on surface quality, MRR and EW of WC-Co, Journal of Materials Processing Technology, 153(1), 1026-1032.

Raji, A.O. and Oke, S.A., 2020, Optimization of EDM for $\mathrm{AA} 6061 / 10 \% \mathrm{Al}_{2} \mathrm{O}_{3}$ AMMC using Taguchi schemes and analytical hierarchy process for weight determination, Kufa Journal of Engineering, 11(3), 42-61.

Rao, G.K.M., Janardhana, G.R., Rao, D.H., Rao, M.S., 2008. Development of hybrid model and optimization of metal removal rate in electric discharge machining using artificial neural networks and genetic algorithm, ARPN Journal of Engineering and Applied Sciences, 209(3), 19-30.

Rao, R.V., Pawar, P.J., 2009. Modeling and optimization of process parameters of wire electrical discharge machining, Proceedings of the Institution of Mechanical Engineers, Journal of Engineering Manufacture, 223(11), 1431-1440.

Sahu S.N., Murmu S.K., Nayak N.C. 2019, Multiobjective optimization of EDM process with performance appraisal of GA based algorithms in neural network environment, Materials Today: Proceedings, 18(7), 3982-3997.

Schumacher B.M., Kramiptz R. and Kruth J.-P., 2013, Historical phase of ED development driven by the dual influence of "market pull" and "science push", Procedia CIRP, 6, 5-12.

Saaty T.L., 2008. Decision making with the analytic hierarchy process, International Journal of Services Sciences, 1(1), 83-98.

Sanghani C.R., Acharya G.D., Kothari K.D. 2020. A simulation-based approach for modeling of fraction of energy transfer to workpiece in electrical discharge machining, International Journal of Manufacturing 
Research, 15(3), 285-296.

Sarma D.K. and Singh M.A. 2020. Machining of thin sections using multi-pass wire electrical discharge machining process, International Journal of Machining and Machinability of Materials, 22(1), 6278.

Song Q., Jiang P., Zheng S. 2021. The application of cloud model combined with non-linear fuzzy analytic hierarchy process for the safety assessment of chemical plant production process, Process Safety and Environmental Protection, 145, 12-22.

Upadhyay L., Aggarwal M.L., Pandey P.M., 2019. Experimental investigations into rotary magnetic field and tool assisted electric discharge machining using magneto rheological fluid as dielectric, International Journal of Mechatronics and Manufacturing Systems, 12(1), 1-19.

Valaki J., Rathod P., Sidpara A., 2018, Sustainability Issues in Electric Discharge Machining, In Innovations in Manufacturing for Sustainability, 5375.

Valaki, J.B., Rathod, P.P. 2016, Assessment of operational feasibility of waste vegetable oil based bio-dielectric fluid for sustainable electric discharge machining (EDM). International Journal of Advanced Manufacturing Technology, 87, 1509-1518.

Vignesh M. and Ramanujam R. 2018. Response optimisation in wire electrical discharge machining of AISI H11 tool steel using Taguchi - GRA approach, International Journal of Machining and Machinability of Materials, 20(5), 474-495.

Yazdi M., Korhan O. \& Daneshvar S. 2020. Application of fuzzy fault tree analysis based on modified fuzzy AHP and fuzzy TOPSIS for fire and explosion in the process industry, International Journal of Occupational Safety and Ergonomics, 26(2), 319-335.

Zhang E., Zhuo J., Hou L., Fu C., Guo T., 2021. Comprehensive annoyance modeling of forklift sound quality based on rank score comparison and multifuzzy analytic hierarchy process, Applied Acoustics, $173,1-8$

Zizlavsky O., 2014, Net present value approach: Method for economic assessment of innovation projects, Procedia-Social and Behavioral Sciences, 156, 506512. 